\title{
Bipolar Spectrum-Substance Use Co-Occurrence: Behavioral Approach System (BAS) Sensitivity and Impulsiveness as Shared Personality Vulnerabilities
}

\author{
Lauren B. Alloy, Rachel E. Bender, \\ Clara A. Wagner, and Wayne G. Whitehouse \\ Temple University \\ Louisa G. Sylvia \\ Massachusetts General Hospital, Harvard Medical School
}

\author{
Lyn Y. Abramson and Michael E. Hogan \\ University of Wisconsin-Madison
}

\author{
Eddie Harmon-Jones \\ Texas A\&M University
}

\begin{abstract}
Bipolar disorders and substance use disorders (SUDs) show high co-occurrence. One explanation for this co-occurrence may be common personality vulnerabilities involved in both. The authors tested whether high behavioral approach system (BAS) sensitivity and impulsiveness are shared personality vulnerabilities in bipolar spectrum disorders and substance use problems and their co-occurrence in a longitudinal study of 132 individuals on the bipolar spectrum and 153 control participants. At Time 1, participants completed the Behavioral Inhibition System/BAS Scales and the Impulsive Nonconformity Scale. Substance use problems were assessed via the Michigan Alcoholism Screening Test and the Drug Abuse Screening Test at 4-month intervals for 1 year. Participants with bipolar disorder had higher rates of lifetime SUDs and substance use problems during the follow-up, relative to control participants. In line with hypotheses, higher BAS sensitivity and impulsiveness predicted bipolar status and increased substance use problems prospectively. BAS total, BAS Fun Seeking, and impulsiveness mediated the association between bipolar spectrum status and prospective substance use problems, with impulsiveness as the most important mediator. High BAS sensitivity and impulsiveness may represent shared personality vulnerabilities for both disorders and may partially account for their co-occurrence.
\end{abstract}

Keywords: bipolar spectrum, substance use, behavioral approach system (BAS) sensitivity, impulsiveness

Theory and evidence have accumulated on the role of long-term personality differences in vulnerability to clinical disorders. The hypothesized behavioral functions of neurobiological systems have provided a way of conceptualizing associations between personality traits and various forms of psychopathology. For example, the reinforcement sensitivity theory (RST) of personality is a broad theory of personality rooted in research and theory on the biological bases of learning and motivation. In Gray's 1982 version, RST posited three systems: (a) the fight-flight system (FFS), (b) the behavioral approach system (BAS), and (c) the behavioral inhibition system (BIS). The FFS was posited to be sensitive to

Lauren B. Alloy, Rachel E. Bender, Clara A. Wagner, and Wayne G. Whitehouse, Psychology Department, Temple University; Lyn Y. Abramson and Michael E. Hogan, Psychology Department, University of Wisconsin-Madison; Louisa G. Sylvia, Massachusetts General Hospital, Harvard Medical School; Eddie Harmon-Jones, Psychology Department, Texas A\&M University.

This research was supported by National Institute of Mental Health Grants MH 52617 and MH 77908 to Lauren B. Alloy and MH 52662 to Lyn Y. Abramson.

Correspondence concerning this article should be addressed to Lauren B. Alloy, Department of Psychology, Temple University, 1701 North 13th Street, Philadelphia, PA 19122. E-mail: lalloy@temple.edu unconditional aversive stimuli; the BAS was posited to be sensitive to conditioned appetitive stimuli; and the BIS was posited to be sensitive to conditioned aversive stimuli, extreme novelty, high-intensity stimuli, and innate fear stimuli. In 2000, Gray and McNaughton revised RST. Now, the FFS was referred to as the fight-flight-freeze system (FFFS), it was posited to be sensitive to all aversive stimuli, BAS was posited to mediate reactions to all appetitive stimuli, and the BIS was now posited to not mediate reactions to conditioned aversive stimuli but to resolve goal conflicts between BAS and FFFS as well as BAS-BAS and FFFSFFFS conflicts (Corr, 2008). In addition to providing a broad theory of personality, RST suggests new ways of thinking about the causes and consequences of clinical disorders. Extreme FFFS sensitivity is posited to underlie disorders such as phobia and panic; extreme BIS sensitivity is posited to underlie disorders such as generalized anxiety and obsessive-compulsive disorder. Extreme BAS sensitivity is posited to underlie addictive behaviors and the appetitive component of mania (Corr, 2008), which is part of bipolar disorder.

Considerable evidence documents high co-occurrence (comorbidity) of bipolar spectrum disorders and substance use disorder (SUDs), even controlling for substance-induced mood disorders and the presence of other Axis I disorders (e.g., Conway, Compton, Stinson, \& Grant, 2006; Regier et al., 1990; Wilens et al., 
2004). Moreover, SUDs may exhibit even higher co-occurrence with bipolar disorder than with other mood or anxiety disorders (Conway et al., 2006; Grant et al., 2004). For example, in a recent nationally representative sample of U.S. adults, the lifetime prevalence of any SUD was $37.5 \%$ among participants with mania versus $20.7 \%$ among participants with unipolar major depression and $19.1 \%$ among participants with any anxiety disorder (Conway et al., 2006). Such bipolar-substance use co-occurrence is mutually detrimental to the course, consequences, and treatment of each condition (Dalton, Cate-Carter, Mundo, Parikh, \& Kennedy, 2003; Salloum \& Thase, 2000; Strakowski et al., 2007). The high cooccurrence between bipolar disorders and SUDs could reflect (a) attempts to self-medicate bipolar mood symptoms with substance use (e.g., Raimo \& Schuckit, 1998), (b) changes in brain functioning leading to mood symptoms as a consequence of repeated substance use, and (c) common vulnerabilities or risk factors involved in both disorders. The present study is designed to examine this last possibility. Specifically, in this study, we investigated the idea that the bipolar spectrum and substance use share the common personality vulnerabilities of enhanced BAS sensitivity and impulsiveness.

\section{BAS Hypersensitivity Theory of Bipolar Disorder and SUD}

As briefly noted above, RST posits that in regulating approach behavior to attain rewards and goals, the BAS is activated by external (e.g., an attractive goal object) or internal (e.g., expectancies of goal attainment) signals of reward (e.g., Depue \& Collins, 1999; Fowles, 1987; Gray, 1991). When these cues activate the BAS, the person increases movement toward attaining goals and cognitive activity (e.g., hope, self-efficacy, planning) aimed at promoting goal attainment. Hope, elation, and happiness are hypothesized to be associated with BAS activation (Depue \& Iacono, 1989; Gray, 1994). Recent work also documents a link between anger and activation of the BAS (Carver, 2004; Harmon-Jones \& Allen, 1998; Harmon-Jones \& Sigelman, 2001), particularly when people have a high expectancy of success for rectifying the angerprovoking situation (Harmon-Jones, Sigelman, Bohlig, \& Harmon-Jones, 2003). The underlying neural substrate of BAS has been hypothesized to involve dopaminergic systems, particularly the mesolimbic dopaminergic pathways with projections from the ventral tegmental area to the nucleus accumbens, amygdala, and prefrontal cortex. This is also one of the critical pathways hypothesized to underlie the positively reinforcing effects of drugs of abuse (e.g., Chambers, Taylor, \& Potenza, 2003; Chiara, 1995; Goldstein \& Volkow, 2002; Jentsch \& Taylor, 1999). In addition, diverse work has converged on the conclusion that activation of the left frontal cortex is a key component of the neural circuitry implementing BAS function (e.g., Coan \& Allen, 2004; Davidson, Jackson, \& Kalin, 2000; Harmon-Jones \& Allen, 1997; Sutton \& Davidson, 1997; Sobotka, Davidson, \& Senulis, 1992).

Depue and colleagues (Depue \& Iacono, 1989; Depue, Krauss, $\&$ Spoont, 1987) proposed a BAS hypersensitivity theory of bipolar disorder (see also Urosevic, Abramson, Harmon-Jones, \& Alloy, 2008, for an update and review of evidence for this theory). According to the BAS theory, individuals vulnerable to bipolar disorder exhibit an overly sensitive BAS that is hyperreactive to relevant cues. A hyperresponsive BAS can lead to excessive BAS activity in response to BAS activation-relevant events involving themes of reward incentive, goal striving and attainment, and anger evocation. Excessive activation of the BAS in vulnerable individuals is hypothesized to be reflected in (hypo)manic symptoms such as euphoria, excessive goal seeking, decreased need for sleep, distractibility, irritability, excessive self-confidence, and optimism (Depue \& Iacono, 1989; Fowles, 1993; Urosevic et al., 2008). According to this view, the high co-occurrence between SUDs and bipolar disorder may be due, in part, to bipolar individuals' excessive pursuit of rewarding stimuli such as druginduced highs. In contrast, according to the theory, depressive symptoms such as sadness, low energy, anhedonia, psychomotor retardation, hopelessness, and low self-confidence reflect a shutdown of behavioral approach or excessive deactivation of the BAS in response to BAS deactivation-relevant events such as definite failure or nonattainment of goals (Depue et al., 1987; Fowles, 1993). A key prediction, then, from the BAS hypersensitivity model is that individuals who have a highly sensitive BAS should be vulnerable to both (hypo)mania and depressive states, that is, to bipolar spectrum disorders.

Much evidence supports the BAS hypersensitivity model of bipolar spectrum disorders. Individuals with bipolar spectrum disorders or exhibiting or prone to hypomanic symptoms show elevated scores on self-reported BAS sensitivity (Alloy et al., 2008; Carver \& White, 1994; B. Meyer, Johnson, \& Carver, 1999; B. Meyer, Johnson, \& Winters, 2001). In addition, high self-reported BAS sensitivity predicted levels of positive affect and hypomanic symptoms among students over 17 days in a daily diary study (T. D. Meyer \& Hofmann, 2005), increases in manic symptoms over 6 months in a recovered bipolar I sample (B. Meyer et al., 2001), a 6 times greater likelihood of a lifetime bipolar spectrum disorder diagnosis among students (Alloy et al, 2006), and a shorter time to onset of hypomanic and manic episodes over 3.5 years in a prospective follow-up of a bipolar spectrum sample (Alloy et al., 2008). Also consistent with the theory, low levels of BAS activation have distinguished individuals with current and recovered major depression from controls (Campbell-Sills, Liverant, \& Brown, 2004; Kasch, Rottenberg, Arnow, \& Gotlib, 2002; Pinto-Meza et al., 2006) and predicted a worse course of depression (Kasch et al., 2002; McFarland, Shankman, Tenke, Bruder, \& Klein, 2006).

Life events hypothesized to be BAS activation relevant, such as goal-attainment (Johnson et al., 2000, 2008) and goal-striving (Nusslock, Abramson, Harmon-Jones, Alloy, \& Hogan, 2007) events, triggered (hypo)manic symptoms or episodes, respectively, in individuals with bipolar disorders. Further, BAS-relevant cognitive styles involving goal striving, perfectionism, and autonomy characterize individuals with bipolar disorders (Alloy et al., in press; Lam, Wright, \& Smith, 2004; Scott, Stanton, Garland, \& Ferrier, 2000) and, in a bipolar spectrum sample, prospectively predicted increases in hypomanic symptoms in combination with congruent positive events and increases in depressive symptoms in combination with congruent negative events (Francis-Raniere, Alloy, \& Abramson, 2006). Similarly, the BAS-relevant personality trait of achievement striving predicted increases in manic symptoms over a 6-month follow-up in a bipolar I sample (Lozano \& Johnson, 2001). Finally, relative left frontal cortical activity (as measured by electroencephalograph, or EEG), a neurobiological index of BAS activity, is increased in mania or proneness to 
hypomania (Harmon-Jones et al., 2002; Kano, Nakamura, Matsuoka, Lida, \& Nakajima,, 1992) and decreased in unipolar and bipolar depression (Allen, Iacono, Depue, \& Arbisi, 1993; Gotlib, Ranganath, \& Rosenfeld, 1998; Henriques \& Davidson, 1990, 1991). Moreover, increased left frontal cortical activity in response to reward incentives in a challenging task distinguished individuals with bipolar spectrum disorders from control participants (Harmon-Jones et al., 2008).

Similarly, several theorists (Dawe \& Loxton, 2004; Dawe, Gullo, \& Loxton, 2004; Franken \& Muris, 2006; Franken, Muris, $\&$ Georgieva, 2006) hypothesized that heightened reward sensitivity or drive (i.e., BAS) contributes to substance use and addiction. For example, it has been suggested that individuals with reward deficit syndrome, who have lower levels of dopamine concentration in neural pathways, are more responsive to the reinforcing effects of rewarding stimuli including drugs and, thus, are more prone to abusing drugs (Blum et al., 2000). Given that high BAS activation leads to approach behavior in situations involving potentially rewarding stimuli and drugs of abuse have rewarding properties, high BAS activation should lead to greater substance use. High BAS sensitivity should also be associated with greater responsiveness to conditioned cues associated with substance use (Kambouropoulos \& Staiger, 2001, 2004) and to using drugs to enhance positive affect or euphoria (Colder \& O’Conner, 2002). Thus, a second prediction from the BAS hypersensitivity model is that individuals with a hypersensitive BAS should be vulnerable to greater problems with substance use. Moreover, BAS hypersensitivity should contribute, at least in part, to the high co-occurrence found between bipolar disorders and substance use.

Although less extensive than the work on BAS and bipolar disorders, growing evidence also supports the BAS hypersensitivity theory for substance use. Cross-sectional and retrospective studies show consistent associations between high self-reported BAS sensitivity and increased substance use and SUDs (Franken \& Muris, 2006; Franken et al., 2006; Johnson, Turner, \& Iwata, 2003; Knyazev, 2004; Loxton \& Dawe, 2001, 2006). Behavioral task measures of BAS sensitivity also differentiate heavy or binge drinkers from light drinkers (Colder \& O'Conner, 2002; Palfai \& Ostafin, 2003) and drinking for enhancement reasons from drinking for coping or social reasons (Colder \& O'Conner, 2002). High BAS sensitivity as measured by self-report or behavioral task is also predictive of greater cravings, intention to drink, and positive affective responses in alcohol cue reactivity paradigms (Franken, 2002; Kambouropoulos \& Staiger, 2001). Few studies have examined EEG frontal cortical asymmetry in association with substance use, and the results of these studies have been mixed (Hayden et al., 2006; Zinser, Fiore, Davidson, \& Baker, 1999). However, an important limitation of most of these studies is that the researchers only examined EEG cortical activity in the resting state. According to the BAS perspective, increased left frontal cortical activity, as an index of BAS, should be observed particularly when approach or incentive motivation is engaged. Thus, consistent with the BAS theory, anticipation of reward (smoking) was associated with increased relative left frontal EEG cortical activity among smokers, and this BAS activation was most pronounced in smokers with the greatest motivation to smoke (those recently withdrawn from nicotine; Zinser et al., 1999).

Thus, much empirical work is consistent with the BAS theory. However, a major shortcoming of this work is that all of the studies on the BAS-substance use association and most of the studies on the BAS-bipolar disorder association are cross-sectional or retrospective. Such designs are not ideal for testing whether BAS sensitivity provides vulnerability to bipolar mood episodes and substance use. Moreover, to our knowledge, no study has examined whether BAS sensitivity mediates the co-occurrence between bipolar disorder and substance use.

\section{Impulsiveness: A Second Common Personality Vulnerability for Substance Use and Bipolar Disorders}

One of the strongest and most consistent personality predictors of substance use is impulsiveness, a tendency toward behavior that is rash, lacks planning and foresight, and occurs without reflection or deliberation (Dawe \& Loxton, 2004). Individual differences in impulsiveness and related behavioral tendencies (e.g., sensation seeking) are associated concurrently with substance misuse and prospectively predict SUDs (Acton, 2003; Dawe et al., 2004). Consistent with recent RST discussions of BAS and impulsiveness (Corr, 2008; Pickering \& Smillie, 2008), investigators have emphasized that impulsiveness is not a unidimensional construct and contains at least two important and separable but correlated dimensions (Dawe \& Loxton, 2004; Dawe et al., 2004): BAS or reward sensitivity (discussed above) and rash impulsiveness (RI) or rash, unplanned, impulsive behavior that occurs without consideration of the consequences. Indeed, recent factor analytic studies show that questionnaire measures of RI (e.g., Eysenck Impulsiveness Scale [Eysenck \& Eysenck, 1991], Barrett Impulsivity Scale [Patton, Stanford, \& Barratt, 1995], Cloninger NoveltySeeking Scale [Cloninger, Przybeck, Svrakic, \& Wetzel, 1994], Zuckerman Sensation-Seeking Scales [Zuckerman, 1994]) load with each other on a separate factor from measures of BAS and reward sensitivity (e.g., BAS from the BIS/BAS Scales [Carver \& White, 1994] and the Sensitivity to Reward scale from the Sensitivity to Punishment Sensitivity to Reward Questionnaire [Torrubia, Avila, Molto, \& Caseras, 2001]), although the two factors are correlated. This RI component is associated with deficits in executive functions of the prefrontal cortex that underlie inhibitory control (Chambers et al., 2003; Dawe et al., 2004), and such PFC executive dysfunction has also been linked to substance misuse (e.g., Bechara \& Damasio, 2002; Bechara, Dolan, \& Hindes, 2002).

Recent integrative models of addiction (Chambers et al., 2003; Dawe \& Loxton, 2004; Dawe et al., 2004; Goldstein \& Volkow, 2002; Jentsch \& Taylor, 1999) suggest that BAS sensitivity and RI act in tandem to contribute to substance use. RI and its associated executive dysfunction lead to the inability to curb substance use once reward (drug)-cued approach behavior (mediated by BAS reward sensitivity or drive) has been initiated. Individuals with high BAS sensitivity may find it particularly difficult to control goal-striving and reward-seeking behaviors, including substance use, and this may be even more likely if they are also high in RI with its concomitant poor inhibitory control. Thus, RI may be a second risk factor for problematic substance use that enhances the effects of heightened BAS sensitivity.

Impulsiveness has also been found to relate to bipolar disorders. Self-report measures of RI are elevated in participants with bipolar spectrum disorders and stable across phases of illness (Swann, Anderson, Dougherty, \& Moeller, 2001; Swann, Dougherty, Paz- 
zaglia, Pham, \& Moeller, 2004). In addition, behaviorally assessed RI is high during manic states (Swann, Pazzaglia, Nicholls, Dougherty, \& Moeller, 2003) and even further elevated in manic individuals with co-occurring SUDs (Swann et al., 2004). Thus, impulsiveness may be a second common vulnerability factor for both substance use and bipolar disorder and may also mediate their co-occurrence.

RI and BAS sensitivity may also interact to affect bipolar disorders. Individuals with hypomanic personality who were low on impulsiveness were least likely to develop bipolar disorder and experienced better outcomes (e.g., fewer arrests) in a longitudinal follow-up (Kwapil, Miller, Zinser, Chapman, \& Eckblad, 2000). Similarly, although students with bipolar spectrum disorders exhibited academic impairment relative to controls, the subgroup that scored high on the BAS Drive subscale but low on impulsiveness was protected from such impairment (Nusslock, Alloy, Abramson, Harmon-Jones, \& Hogan, 2008).

\section{The Present Study}

Thus, the goal of the present 1-year longitudinal study was to examine BAS sensitivity and impulsiveness as predictors of bipolar disorder status and substance use (alcohol and drugs) and their co-occurrence in a sample of late adolescents and young adults with bipolar spectrum disorders and demographically matched control participants. Despite the high prevalence of comorbidity between bipolar spectrum disorders and substance use, studies have yet to examine the potential role of BAS sensitivity and impulsiveness in their co-occurrence. We hypothesized that both high self-reported BAS sensitivity and high self-reported impulsiveness (a) would be associated with lifetime bipolar spectrum and SUD diagnosis (Hypothesis 1), (b) would predict substance use problems prospectively (Hypothesis 2 ), and (c) would mediate the co-occurrence of bipolar disorder and substance use (Hypothesis 3). We also explored whether high impulsiveness mediated or moderated the association of high BAS sensitivity with bipolar disorder status, substance use, and their co-occurrence.

\section{Method}

\section{Participants}

Participants were part of a larger prospective longitudinal study of the psychosocial, cognitive, and biological predictors of the course of bipolar spectrum disorders. They were selected via a two-stage screening process. In Phase I, approximately 20,500 18to 24-year-old students at a large northeastern university and a large midwestern university completed the revised General Behavior Inventory (GBI; Depue et al., 1981). Those who met the GBI cutoff scores recommended by Depue et al. (1981; see the Measures section below) to identify individuals on the bipolar spectrum and control participants were invited to participate in Phase II, which involved an interview with the expanded Schedule for Affective Disorders and Schizophrenia-Lifetime (exp-SADS-L; Endicott \& Spitzer, 1978) diagnostic interview. Diagnoses were assigned on the basis of the Diagnostic and Statistical Manual for Mental Disorders (4th ed.; DSM-IV; American Psychiatric Association, 1994) and/or Research Diagnostic Criteria (Spitzer, Endicott, \& Robins, 1978). Those receiving a diagnosis of bipolar II disorder or cyclothymia were invited to participate in the longitudinal study. Participants with a lifetime history of mania were excluded from the final sample, as a goal of the larger project was to assess risk factors for the development of full-blown bipolar I disorder in those with milder bipolar spectrum conditions. During Phase II, lifetime history of alcohol and substance abuse and dependence was also assessed via the exp-SADS-L.

Control participants were recruited and matched with participants on the bipolar spectrum on age, sex, and ethnicity. Only those control participants with no lifetime history of Axis I psychopathology (with the exception of specific phobia) ${ }^{1}$ and no family history of mood disorders were included in the final sample. Informed consent was obtained from all participants prior to their participation in the study.

The final sample consisted of 149 participants with bipolar II disorder (56 men, 93 women) and 57 participants with cyclothymia (23 men, 34 women), with a mean age of 19.6 years ( \pm 1.6 years). Among participants with bipolar spectrum disorders, the ethnic composition was $68.9 \%$ Caucasian, $13.1 \%$ African American, 5.1\% Hispanic, 3.6\% Asian, 0.5\% Native American, and $8.2 \%$ other. Only 31 of the participants with bipolar spectrum disorders (15\%) had sought treatment (medication or psychotherapy) prior to their entry into the study, whereas $63(30.6 \%)$ sought treatment during the follow-up. Of those who sought treatment after inclusion in the study, $32(15.5 \%)$ received medication, $26(12.6 \%)$ received psychotherapy only, and 7 (3.4\%) were hospitalized (of these, 2 received other treatment as well). The final control sample consisted of 208 participants (86 men, 122 women) with a mean age of 19.7 years $( \pm 1.5$ years). The ethnic composition of the control participants was $72.8 \%$ Caucasian, $12.1 \%$ African American, 3.4\% Hispanic, $4.4 \%$ Asian, $0.5 \%$ Native American, and $6.8 \%$ other.

Only participants with complete data on impulsivity and BAS sensitivity were included in the present analyses, resulting in a final sample for this study of 132 participants with bipolar spectrum disorders (98 bipolar II, 34 cyclothymia) and 153 control participants. Demographic and clinical characteristics of the current sample are presented as a function of diagnosis in Table 1. Overall, 59.6\% $(n=170)$ were women. Participant ages ranged from 18 to 24 years with a mean age of 19.65 years ( \pm 1.74 years). Gender, age, and ethnicity did not differ significantly by diagnosis, $\chi^{2}(1, N=285)=0.094, p=.760 ; t(211)=-0.095, p=.924 ;$ and $\chi^{2}(5, N=213)=3.40, p=.639$, respectively.

\footnotetext{
${ }^{1}$ During the end of the recruitment period of the Longitudinal Investigation of Bipolar Spectrum Project sample, it was becoming difficult to complete the recruitment of control participants matched to the participants in the bipolar group on age, sex, and ethnicity, who had no history of any Axis I disorders. We found that some of the control participants who matched the participants with bipolar disorder on demographics had a prior history of a single specific phobia (e.g., of spiders). Thus, we decided to allow control participants with a history of one specific phobia into the control group. Control participants with a specific phobia represented a small proportion (about 5\%) of the total control group. From an RST perspective, the presence of some control participants with specific phobia could lead the control group to score higher than the bipolar group on BIS sensitivity. However, this was not the case: The two groups did not differ on BIS sensitivity (see Table 1).
} 
Table 1

Sample Demographic and Clinical Characteristics $(N=285)$

\begin{tabular}{lcc}
\hline \multicolumn{1}{c}{ Characteristic } & Control & $\begin{array}{c}\text { Bipolar } \\
\text { spectrum }\end{array}$ \\
\hline$n$ & 153 & 132 \\
Age in years & $19.64(1.84)$ & $19.66(1.63)$ \\
Gender (female) & $58.8 \%$ & $60.6 \%$ \\
Ethnicity & $77.9 \%$ & \\
$\quad$ Caucasian & $8.8 \%$ & $75.0 \%$ \\
African American & $3.5 \%$ & $14.0 \%$ \\
Hispanic & $1.8 \%$ & $4.0 \%$ \\
Asian & $0.0 \%$ & $1.0 \%$ \\
Native American & $8.0 \%$ & $1.0 \%$ \\
Other & $37.85^{* * * *}(5.12)$ & $40.96^{* * * *}(5.34)$ \\
BAS total & $10.42^{* * * *}(2.38)$ & $11.57^{* * * *}(2.34)$ \\
BAS Drive & $16.41^{*}(1.93)$ & $19.98^{* *}(1.98)$ \\
BAS Reward Responsiveness & $10.99^{* * * *}(2.26)$ & $12.42^{* * * *}(2.38)$ \\
BAS Fun Seeking & $20.15(3.14)$ & $20.83(3.75)$ \\
BIS & $9.50^{* * * *}(6.56)$ & $17.42^{* * * *}(8.63)$ \\
Impulsive Nonconformity & & \\
Lifetime substance diagnosis (any) ${ }^{\mathrm{a}}$ & & $24.5 \%$ \\
$\quad$ Yes & & $75.5 \%$ \\
No & & $2.53^{* * * *}(1.26)$ \\
MAST-DAST average & $1.91^{* * * *}(0.89)$ & \\
\hline
\end{tabular}

Note. Means are presented with standard deviations in parentheses. MAST $=$ Michigan Alcoholism Screening Test; DAST $=$ Drug Abuse Screening Test.

${ }^{a}$ Individuals with a lifetime history of substance abuse or dependence were screened out of the normal control group. Thus, lifetime history of substance dependence is not reported for the normal control group.

${ }^{*} p<.05 .{ }^{* * *} p<.01 .{ }^{* * *} p<.001$.

\section{Procedure}

At Time 1, participants completed the Beck Depression Inventory (BDI; Beck, Rush, Shaw, \& Emery, 1979), the Halberstadt Mania Inventory (HMI; Alloy, Reilly-Harrington, Fresco, Whitehouse, \& Zechmeister, 1999), the BIS/BAS Scales (Carver \& White, 1994), and the Impulsive Nonconformity Scale (IN; Chapman et al., 1984). Approximately every 4 months over the prospective follow-up period, participants were interviewed with an expanded SADS-Change diagnostic interview (exp-SADS-C) to assess the occurrence of major depressive, hypomanic, and manic episodes over the past 4 months. In addition, at each 4-month interval, participants completed the Michigan Alcoholism Screening Test (MAST; Selzer, 1971) and the Drug Abuse Screening Test (DAST; Skinner, 1992). The present study was based on data from the first three follow-up periods (1 year). All participants were reimbursed for their time as follows: $\$ 5$ for Phase I completion of GBI; \$25 for Phase II completion of exp-SADS-L; $\$ 80$ for completion of all baseline measures at first regular prospective assessment; $\$ 50$ for all subsequent regular prospective assessments.

\section{Measures}

GBI (Depue et al., 1981; Depue, Krauss, Spoont, \& Arbisi, 1989). The GBI is a 73-item self-report questionnaire designed as a cost-effective and rapid first-stage screening method for identifying individuals with bipolar spectrum disorders. Items assess the intensity, duration, and frequency of bipolar symptoms. The inventory has two subscales: a Depression subscale (GBI-D) and a combined Hypomanic and Biphasic subscale (GBI-HB). Participants rate the frequency with which each symptom occurs on a 4-point scale, with 1 representing never and 4 representing very often or almost constantly. In line with Depue et al. (1981, 1989), we used a case scoring method, in which one point was added to the total score for all items rated 3 (often) or 4 (very often). Participants who exceeded Depue et al.'s (1981) recommended cutoff scores (GBI-D $\geq 11$; GBI-HB $\geq 13$ ) were considered potential participants for the bipolar group and those who scored below these cutoffs were considered potential control participants; members of both of these groups were invited to participate in Phase II. In past research (Depue et al., 1989), the GBI has shown good internal consistency $(\alpha$ s $=.90-.96)$, high specificity $(r=.99)$, and adequate sensitivity $(r=.78)$ and test-retest reliability $(r=.71-.74)$. In addition, it has shown good discriminant validity, correctly identifying those with affective disorders among those with nonaffective disorders (Mallon, Klein, Bornstein, \& Slater, 1986) and has been validated in a variety of samples, including university students, individuals with a parental history of bipolar disorder, and outpatients (Depue et al., 1981, 1989; Klein, Depue, \& Slater, 1986).

Exp-SADS-L (Endicott \& Spitzer, 1978). The exp-SADS-L is a semistructured diagnostic interview that assesses current and lifetime history of Axis I disorders, including lifetime history of alcohol and substance abuse and dependence. To increase reliability and accuracy in diagnosing bipolar spectrum disorders, we expanded the SADS-L and SADS-C (see below for an overview of the exp-SADS-C) interviews in consultation with Akiskal, Angst, Clayton, Endicott, and Gruenberg, who are experts on bipolar disorders. The following alterations were made to the exp-SADS-L:

1. Additional probes were included to allow for the assignment of $D S M-I V$ diagnoses in addition to research diagnostic criteria diagnoses.

2. In the Depression, Mania, Hypomania, and Cyclothymia sections, the number of items was expanded and additional probes were incorporated to capture details regarding episodes and frequency and duration of symptoms.

3. Additional probes were added to assess the precise number of days and percentage of waking hours participants felt depressed, euphoric, or irritable in the Depression, Mania, and Hypomania sections, respectively.

4. Probes in the Depression, Mania, Hypomania, and Cyclothymia sections were improved on the basis of Depue's (1985) Behavioral Variability Interview.

5. In the Cyclothymia section, items were added to assess the frequency, duration, and switch rapidity of the depressive and hypomanic periods.

6. Probes were added to examine the extent to which participants' changes in behavior were noted by people in their lives.

7. For each symptom item, a 5-point scale was used (0-4), with a rating of 3 representing the cutoff score for the clinical presence of the symptom. 
8. Sections assessing past episodes of depression, mania, and hypomania were placed immediately following their corresponding current sections to enhance clarity and facilitate comprehension.

9. Sections were added assessing eating disorders, ADHD, and acute stress disorder.

10. Additional probes were included in the anxiety disorders section.

11. An organic rule-out module and a medical history section were appended.

The exp-SADS-L interview has demonstrated good interrater reliability for diagnoses of major depressive episodes $(\kappa s>.95)$ and all unipolar diagnoses $(\kappa \mathrm{s}>.90)$ on the basis of 80 jointly rated interviews in a previous study (Alloy et al., 2000) and for bipolar spectrum diagnoses $(\kappa s>.96)$ in the current project on the basis of 105 jointly rated interviews. Interviews were conducted by research assistants who had completed over $200 \mathrm{hr}$ of training and were blind to participants' Phase I GBI scores, BIS/BAS Scales scores, and IN scores. Consensus DSM-IV and Research Diagnostic Criteria diagnoses were determined by a three-tiered standardized diagnostic review procedure involving senior diagnosticians and an expert psychiatric diagnostic consultant, Alan Gruenberg.

BIS/BAS Scales (Carver \& White, 1994). The BIS/BAS Scales are the self-report measures most widely used to assess sensitivity of the BIS and BAS. The scales consist of 20 items that are rated on a 4-point Likert-type scale $(1=$ strongly disagree, 4 = strongly agree) and comprise three BAS subscales and one BIS subscale. The BAS Reward Responsiveness subscale has five items designed to assess positive response to reward stimuli. The BAS Drive subscale has four items indicative of persistence in pursuit of reward. The BAS Fun Seeking subscale contains four items indicative of willingness to approach novel and rewarding stimuli. All subscales have adequate internal consistency $(\alpha s=.66-.76)$ and test-retest reliability ( $r$ s $=.59-.69$; Carver \& White, 1994). The BIS/BAS Scales have demonstrated construct validity; they have been associated with prefrontal cortical activity, affect, personality traits, and performance on reaction-time and learning tasks involving incentives (Colder \& O'Conner, 2004; Harmon-Jones \& Allen, 1997; Kambouropoulos \& Staiger, 2004; Sutton \& Davidson, 1997; Zinbarg \& Mohlman, 1998). The items on the BAS Scales did not overlap in content with the items from the exp-SADS-L and exp-SADS-C interviews used to assess the (hypo)manic symptom criteria for a bipolar spectrum disorder diagnosis or with items on our self-report measure of (hypo)manic symptoms (HMI; see below). Moreover, Alloy et al. (2008, Table 2) reported that the correlations between the HMI and the BAS total and BAS subscales ranged from .038 to .214 , corresponding to a maximum of $4.6 \%$ of shared variance. Thus, the BAS scales appear to measure a distinct construct of behavioral approach, sufficiently distinct from (hypo)manic symptoms themselves.

IN (Chapman et al., 1984). The IN consists of 51 true-false items that tap impulsive behavior. Items include "When I want something, delays are unbearable," and "I avoid trouble whenever I can" (reverse scored). The IN has good internal consistency ( $\alpha$ s = .79-.84; Alloy et al., 2006; Chapman et al., 1984) and 6-week retest reliability ( $r=.84$; Chapman et al., 1984). Chapman et al. (1984) found that individuals who scored high on the IN were more likely to endorse antisocial, psychotic, depressive, and hypomanic/manic symptoms than were those in a control group. Moreover, Alloy et al. (2006) found that individuals high in BAS sensitivity exhibited higher IN scores than did individuals with moderate BAS sensitivity.

BDI (Beck et al., 1979). The BDI is a 21-item self-report scale that assesses affective, motivational, cognitive, and somatic symptoms of depression. Participants select among four statements graded in severity, which are weighted from 0 to 3 , with 3 representing the highest level of symptom severity. Total scores range from 0 to 63 . The BDI has demonstrated good internal consistency, retest reliability, and concurrent validity with clinical depression ratings in both clinical $(r=.72)$ and nonclinical $(r=$ .60) samples. Furthermore, it has been validated in samples of undergraduates (Beck, Steer, \& Garbin, 1988).

HMI (Alloy et al., 1999). The HMI is a 28-item self-report questionnaire, modeled after the BDI, designed to assess current affective, motivational, cognitive, and somatic symptoms of (hypo)mania. As with the BDI, participants select one of four statements representing differing degrees of symptom severity (e.g., I do not feel particularly happy, I feel happy, I feel so happy and cheerful it's like a high, and I am bursting with happiness and I'm on top of the world). In the Longitudinal Investigation of Bipolar Spectrum Project, the HMI demonstrated construct validity and was correlated ( $r=.46$ ) with hypomanic symptoms reported on the exp-SADS-C interview (Alloy et al., 2008). Moreover, as would be expected, cyclothymic individuals reported HMI scores consistent with their current mood state, reporting significantly more hypomanic symptoms on the HMI when they were in hypomanic states $(M=23.9)$ than when they were in depressed $(M=$ 15.7) or euthymic states $(M=18.8)$. In a sample of 1,282 undergraduates (Alloy et al., 1999), the HMI showed high internal consistency $(\alpha=.82$ ), adequate convergent validity with the mania scale of the Minnesota Multiphasic Personality Inventory $(r=.32, p<.001)$, and adequate discriminant validity both with the Minnesota Multiphasic Personality Inventory Depression Scale $(r=-.26, p<.001)$ and with the BDI $(r=-.12, p<.001)$.

Exp-SADS-C (Spitzer \& Endicott, 1978). The exp-SADS-C interview was administered at 4-month intervals over the prospective follow-up period. It was used to assess onset, duration, and severity of symptoms and episodes of Axis I psychopathology, including major depressive, manic, and hypomanic episodes. Interviewers were blind to the diagnostic status of participants, as well as to their GBI, BIS/BAS Scales, and IN scores. The SADS-C was expanded in the same manner as the SADS-L. In addition, it also incorporated features of the Longitudinal Interval Follow-up Evaluation (Shapiro \& Keller, 1979). This allowed detailed tracking of the course of symptoms and episodes over each 4-month period. In the current project, the exp-SADS-C demonstrated good interrater reliability $(\kappa>.80)$ in joint ratings of 60 interviews. Moreover, in a validity study, participants reported the dates of their symptoms on the exp-SADS-C with at least $70 \%$ accuracy relative to daily symptom ratings made over a 4-month interval.

MAST (Selzer, 1971). The MAST is a commonly used selfreport questionnaire designed to screen for alcohol use problems. It has 24 items assessing symptoms of alcohol abuse and dependence. Items are given a score of $0,1,2$, or 5 and are summed to 
yield total MAST scores ranging from 0 to 53, with higher scores indicating greater alcohol use problems. The MAST has shown good reliability (Marion, Fuller, Johnson, Michels, \& Diniz, 1996) and sensitivity (Maisto, Connors, \& Allen, 1995), adequate internal consistency (Conley, 2001), construct validity (Conley, 2001), and good concurrent validity with $D S M-I V$ diagnostic criteria (Watson, Detra, Fox, \& Ewing, 1995). The MAST was administered regularly at 4-month intervals, and participants were asked to provide separate responses for each individual month. Cronbach's $\alpha$ for dichotomized initial MAST scores in the present sample was .64 , which falls within the range reported in a recent reliability meta-analysis of the MAST (Shields, Howell, Potter, \& Weiss, 2007).

DAST (Skinner, 1992). The DAST is a self-report questionnaire designed to assess drug use problems. It consists of 28 yes-no items indicative of symptoms of drug use and dependence. Items are weighted 0 or 1 , and responses are summed to yield a total score ranging from 0 to 28 , with higher scores indicating higher levels of drug use problems. The DAST has shown good validity and reliability (Cocco \& Carey, 1998; El-Bassel et al., 1997; Lin, Lee, Pan, \& Hu, 2003; McCann, Simpson, Ries, \& Roy-Byrne, 2000). Furthermore, it has been validated for use in both psychiatric and community settings (Cocco \& Carey, 1998; El-Bassel et al., 1997; Klamen \& Miller, 1997; Lin et al., 2003). As with the MAST, the DAST was administered at each follow-up assessment and yielded monthly ratings of drug use problems. Cronbach's $\alpha$ for dichotomized initial DAST scores in the present sample was .65 .

Given that we were interested in the prediction of general substance use problems, rather than of any one particular substance, MAST and DAST scores were combined to obtain an overall measure of substance use problems. Specifically, we calculated mean MAST scores across the first three follow-up assessments and mean DAST scores across the same three follow-up assessments. We then averaged MAST and DAST scores to create a composite score representing general substance use problems over the 1-year follow-up period.

\section{Results}

\section{Diagnostic Group Differences in BAS Sensitivity, Impulsiveness, and Substance Use Problems}

Table 1 presents means and standard deviations of BAS total, BAS subscale, BIS, IN, and average MAST and DAST composite scores. Participants in the bipolar group evidenced significantly higher BAS total, $t(278)=-4.95, p<.001$; BAS Drive, $t(280)=$ $-4.06, p<.001$; BAS Reward Responsiveness, $t(281)=-2.41$, $p=.017$; and BAS Fun Seeking, $t(283)=-5.20, p<.001$, scores than did control participants. Participants in the bipolar group also scored significantly higher on the IN than did control participants, $t(283)=-8.76, p<.001$. There were no significant group differences on BIS scores, $t(283)=-1.67, p=.097$. Finally, participants in the bipolar group had significantly higher average MAST and DAST composite scores over the 1-year follow-up, $t(275)=-4.79, p<.001$.

\section{Associations Among BAS Sensitivity, BIS Sensitivity, and Impulsiveness}

Pearson correlations were conducted to examine whether the BAS/BIS Scales and IN assess unique or overlapping constructs. Intercorrelations between BAS total, BAS subscales, BIS, and IN scores are presented in Table 2. BAS total and IN scores were significantly positively correlated $(r=.41, p<.001)$, but the correlation was moderate and corresponds to only $16.81 \%$ shared variance. Thus, consistent with their theoretical origins, these instruments appear to measure overlapping but distinct constructs Likewise, IN scores were significantly positively correlated with BAS Drive $(r=.35, p<.001)$ and BAS Fun Seeking $(r=.49$, $p<.001)$ scores, but again these correlations were moderate and correspond to only $12.25 \%$ and $24.01 \%$ shared variance, respectively. BIS scores were negatively correlated with IN scores $(r=$ $-.14, p=.018)$ but were not correlated with BAS total $(r=.03$, $p=.637)$ or any of the BAS subscales, except for BAS Reward Responsiveness $(r=.275, p<.001)$.

\section{Lifetime and Prospective Associations Between Bipolar Spectrum Diagnosis and Substance Use}

We first examined the association between lifetime history of SUDs and bipolar spectrum diagnosis. In line with previous research, we expected higher rates of lifetime SUDs among those with bipolar spectrum disorders compared with control participants. Because lifetime history of SUD was an exclusion criterion for control participants in the longitudinal study, we were unable to compare rates of lifetime SUDs by diagnostic status in our analysis sample. Instead, we examined lifetime prevalence rates of SUDs among those who completed our Phase II diagnostic inter-

Table 2

Intercorrelations Between the Behavioral Approach System (BAS) Scale, BAS Subscales, Impulsive Nonconformity, and Behavioral Inhibition System (BIS) Scale

\begin{tabular}{|c|c|c|c|c|c|c|}
\hline Scale & 1 & 2 & 3 & 4 & 5 & 6 \\
\hline 1. BAS total & - & & & & & \\
\hline 2. BAS Drive & $.83^{* * * *}$ & - & & & & \\
\hline 3. BAS Reward Responsiveness & $.74^{* * * *}$ & $.42^{* * *}$ & - & & & \\
\hline 4. BAS Fun Seeking & $.82^{* * * *}$ & $.51^{* * *}$ & $.41^{* * * *}$ & - & & \\
\hline 5. Impulsive Nonconformity & $.41^{* * * *}$ & $.35^{* * *}$ & .11 & $.49^{\text {***** }}$ & - & \\
\hline 6. BIS & .03 & -.09 & $.28^{* * * *}$ & -.08 & $-.14^{*}$ & - \\
\hline
\end{tabular}


view. Specifically, from the Phase II sample, we compared rates of lifetime SUDs among participants with bipolar spectrum disorders (bipolar I, II, or cyclothymia; $n=204$ ), those with a history of major depressive episode(s) but no (hypo)mania $(n=251)$, and those without a history of either (hypo)mania or major depression $(n=449)$. Consistent with results reported in the literature, rates of lifetime SUDs differed significantly among those with bipolar spectrum disorder $(28.4 \%)$, those with a history of major depressive episode(s) but no (hypo)mania $(21.1 \%)$, and those without a history of any mood disorder $(14.5 \%), \chi^{2}(2, N=904)=18.02$, $p<.001$. Pairwise comparisons revealed that participants with bipolar spectrum disorders had significantly higher rates of SUDs than those without a history of (hypo)mania or major depression, $\chi^{2}(1, N=653)=17.87, p<.001$. Participants with bipolar spectrum disorders also showed higher rates of SUDs than individuals with histories of major depression only, and this effect approached significance, $\chi^{2}(1, N=455)=3.27, p=.07$.

We also examined the association between bipolar spectrum status and prospective substance use problems (as measured by the combined average of monthly MAST and DAST scores), controlling for lifetime SUD. Despite gender differences in mean combined MAST-DAST scores, gender was not a significant predictor of prospective substance use problems in any of our regression models and, therefore, was not included as a covariate in final analyses. A linear regression revealed that bipolar spectrum status significantly predicted prospective substance use problems $(\beta=$ $.164, p=.005)$, controlling for lifetime history of SUD. Thus, compared with control participants, bipolar spectrum individuals exhibited elevated rates of substance use, both lifetime SUDs and prospective substance use problems. Given the demonstrated association between bipolar spectrum disorders and substance use problems in this sample, we next tested our remaining hypotheses, namely, whether BAS sensitivity and IN scores represent shared vulnerabilities for both and whether they can account for their co-occurrence.

\section{Associations of BAS Sensitivity and Impulsiveness With Bipolar Spectrum Status}

Logistic regression analyses were conducted to examine the hypothesis that BAS sensitivity and IN scores would be related to bipolar diagnostic status. Results are presented in Table 3. We did not control for any demographic variables, as none were predictive of bipolar spectrum status. BAS total scores were associated sig- nificantly with diagnostic status, with higher levels of BAS sensitivity among those with bipolar spectrum disorder relative to control participants. We also examined the contribution of each of the three BAS subscales (Reward, Drive, and Fun Seeking) to the prediction of bipolar spectrum status and found that all three were associated significantly with diagnostic status, with higher levels of sensitivity among those with a bipolar spectrum disorder relative to control participants. Controlling for initial depressive (BDI) and hypomanic (HMI) symptom levels, we found that BAS total and BAS Fun Seeking continued to be associated significantly with bipolar spectrum status $(B=.084, S E B=.038, p=.028$, and $B=.202, S E B=.081, p=.012$, respectively). However, BAS Drive became marginally associated with bipolar diagnostic status $(B=.142, S E B=.082, p=.083)$, and BAS Reward Responsiveness was no longer associated $(B=.065, S E B=.090$, $p=.470)$. BIS was marginally associated with diagnostic status and became nonsignificant after controlling for initial symptom levels $(B=.016, S E B=.055, p=.774)$. Logistic regression analyses also revealed that IN scores were associated significantly with diagnostic status, with higher IN scores among participants in the bipolar group than among control participants. This finding remained significant even after controlling for initial symptom levels $(B=.078, S E B=.545, p<.001)$.

\section{BAS Sensitivity and Impulsiveness as Predictors of Prospective Substance Use Problems}

Next, we conducted a series of hierarchical linear regression analyses to examine whether BAS sensitivity and IN scores predicted prospective substance use problems over the 1-year follow-up period. Again, we controlled for lifetime SUD diagnosis in our analyses. Results are presented in Table 4. As hypothesized, BAS total scores and IN scores each significantly predicted prospective substance use problems over the follow-up, controlling for lifetime SUD diagnosis. With regard to the BAS subscales, BAS Fun Seeking significantly predicted prospective substance use problems; however, the BAS Reward Responsiveness subscale, BAS Drive subscale, and BIS scores did not.

\section{Examination of the Interaction Between BAS Sensitivity and Impulsiveness}

Given that BAS and IN scores do represent distinct constructs in our data, we explored whether IN scores moderated the association

Table 3

Logistic Regression Models of Associations of the Behavioral Approach System (BAS) Scale Total, BAS Subscales, Behavioral Inhibition System (BIS) Scale, and Impulse Nonconformity With Bipolar Spectrum Status

\begin{tabular}{lcccccc}
\hline \multicolumn{1}{c}{ Scale } & $\beta$ & $S E \beta$ & Wald & OR & $95 \%$ CI & $p$ \\
\hline BAS total & .12 & .03 & 21.78 & 1.12 & $1.07-1.18$ & $<.001$ \\
BAS Fun Seeking & .27 & .06 & 24.29 & 1.31 & $1.18-1.46$ & $<.001$ \\
BAS Drive & .20 & .05 & 14.42 & 1.22 & $1.10-1.35$ & $<.001$ \\
BAS Reward Responsiveness & .16 & .06 & 6.44 & 1.17 & $1.04-1.32$ & .01 \\
BIS & .07 & .04 & 3.52 & 1.07 & $1.00-1.14$ & .06 \\
Impulsive Nonconformity & .13 & .02 & 49.17 & 1.14 & $1.10-1.18$ & $<.001$ \\
\hline
\end{tabular}

Note. $\quad \mathrm{OR}=$ odds ratio; $\mathrm{CI}=$ confidence interval. 
Table 4

Summary of Linear Regression Models of BAS, BAS Subscales, BIS, and Impulsive Nonconformity Predicting MAST-DAST Average Over the 1-Year Follow-Up

\begin{tabular}{|c|c|c|c|c|c|}
\hline Predictor & $B$ & $S E \mathrm{~B}$ & $\beta$ & $t$ & $p$ \\
\hline \multicolumn{6}{|l|}{ Model 1} \\
\hline \multicolumn{6}{|l|}{ Step 1} \\
\hline Lifetime SUD & 0.77 & 0.24 & .22 & 3.20 & $<.01$ \\
\hline \multicolumn{6}{|l|}{ Step 2} \\
\hline Lifetime SUD & 0.73 & 0.24 & .21 & 3.07 & $<.01$ \\
\hline BAS total & 0.04 & 0.01 & .18 & 2.75 & $<.01$ \\
\hline \multicolumn{6}{|l|}{ Model 2} \\
\hline \multicolumn{6}{|l|}{ Step 1} \\
\hline Lifetime SUD & 0.91 & 0.24 & .25 & 3.79 & $<.001$ \\
\hline \multicolumn{6}{|l|}{ Step 2} \\
\hline Lifetime SUD & 0.82 & 0.23 & .23 & 3.50 & $<.01$ \\
\hline BAS Fun Seeking & 0.11 & 0.03 & .24 & 3.77 & $<.001$ \\
\hline \multicolumn{6}{|l|}{ Model 3} \\
\hline $\begin{array}{l}\text { Step } 1 \\
\quad \text { Lifetime SUD }\end{array}$ & 0.90 & 0.24 & .25 & 3.74 & $<.001$ \\
\hline \multicolumn{6}{|l|}{ Step 2} \\
\hline Lifetime SUD & 0.89 & 0.24 & .25 & 3.69 & $<.001$ \\
\hline BAS Drive & 0.04 & 0.03 & .09 & 1.40 & .16 \\
\hline \multicolumn{6}{|l|}{ Model 4} \\
\hline \multicolumn{6}{|l|}{ Step 1} \\
\hline Lifetime SUD & 0.78 & 0.24 & .22 & 3.25 & $<.01$ \\
\hline \multicolumn{6}{|l|}{ Step 2} \\
\hline Lifetime SUD & 0.77 & 0.24 & .22 & 3.21 & $<.01$ \\
\hline BAS Reward & 0.06 & 0.04 & .10 & 1.55 & .12 \\
\hline \multicolumn{6}{|l|}{ Model 5} \\
\hline \multicolumn{6}{|l|}{ Step 1} \\
\hline Lifetime SUD & 0.91 & 0.24 & .25 & 3.79 & $<.001$ \\
\hline \multicolumn{6}{|l|}{ Step 2} \\
\hline Lifetime SUD & 0.92 & 0.24 & .25 & 3.82 & $<.001$ \\
\hline BIS & 0.02 & 0.02 & .07 & 1.03 & .31 \\
\hline \multicolumn{6}{|l|}{ Model 6} \\
\hline \multicolumn{6}{|l|}{ Step 1} \\
\hline Lifetime SUD & 0.86 & 0.24 & .24 & 3.55 & $<.001$ \\
\hline \multicolumn{6}{|l|}{ Step 2} \\
\hline Lifetime SUD & 0.62 & 0.25 & .17 & 2.54 & .012 \\
\hline Impulsiveness & 0.03 & 0.01 & .24 & 3.55 & $<.001$ \\
\hline
\end{tabular}

Note. $\quad$ SUD $=$ substance use disorder; BAS $=$ Behavioral Approach System Scale; BIS = Behavioral Inhibition System Scale; MAST = Michigan Alcoholism Screening Test; DAST = Drug Abuse Screening Test; Fun Seeking $=$ Fun Seeking subscale; Drive $=$ Drive subscale; Reward $=$ Reward Responsiveness subscale. In Model $1, R^{2}=.047$ and $F(1,208)=10.25$ for Step $1(p=.002) ; \Delta R^{2}=.034$ and $\Delta F(1,207)=$ 7.586 for Step $2(p=.006)$. In Model $2, R^{2}=.063$ and $F(1,213)=$ 14.36 for Step $1(p=.000) ; \Delta R^{2}=.059$ and $\Delta F(1,212)=14.24$ for Step $2(p=.000)$. In Model 3, $R^{2}=.062$ and $F(1,210)=13.99$ for Step $1(p=.000) ; \Delta R^{2}=.009$ and $\Delta F(1,209)=1.953$ for Step $2(p=$ .164). In Model $4, R^{2}=.048$ and $F(1,211)=10.559$ for Step $1(p=$ $.001) ; \Delta R^{2}=.011$ and $\Delta F(1,210)=2.402$ for Step $2(p=.123)$. In Model $5, R^{2}=.063$ and $F(1,213)=14.361$ for Step $1(p=.000)$; $\Delta R^{2}=.005$ and $\Delta F(1,212)=1.059$ for Step $2(p=.305)$. In Model $6, R^{2}=.056$ and $F(1,211)=12.614$ for Step $1(p=.000) ; \Delta R^{2}=.053$ and $\Delta F(1,210)=12.606$ for Step $2(p=.000)$.

between BAS and (a) bipolar spectrum status or (b) prospective substance use problems. Each of the previously tested models predicting bipolar status or prospective substance use problems was reanalyzed with predictors entered into the model in the following order: lifetime history of SUD diagnosis entered in Step 1 (when prospective substance use problems was the dependent variable); BAS, a BAS subscale, or BIS entered in Step 2; IN scores entered in Step 3; and the interaction term $(\mathrm{BAS} \times \mathrm{IN}$, a BAS Subscale $\times$ IN, or BIS $\times$ IN) entered in Step 4. Results for these tests of moderation are presented in Tables 5 and 6 , with results predicting bipolar spectrum status presented in Table 5 and results predicting prospective substance use presented in Table 6 . In no case were any of the interaction terms significant, indicating that BAS and IN did not interact to predict either bipolar spectrum status or substance use problems, over and above the prediction afforded by either construct alone.

\section{Shared Vulnerability: Test of a Mediation Model}

In summary, the findings above suggest (a) that bipolar spectrum status is associated with prospective substance use, (b) that BAS sensitivity and impulsiveness both are associated with bipolar spectrum status, and (c) that BAS sensitivity and impulsiveness both are associated with prospective substance use. Therefore, we were able to test our final hypothesis that the positive association between bipolar spectrum status and prospective substance use problems might be attributable in part to the shared personality factors of BAS sensitivity and impulsiveness. Such mediation hypotheses are often tested using the causal steps approach popularized by Baron and Kenny (Baron \& Kenny, 1986) or the product-of-coefficients approach developed by Sobel (Sobel, 1982 , 1986). Both procedures use parametric techniques that assume multivariate normality of the sampling distribution of total and specific indirect effects, which can be problematic except in very large samples (MacKinnon, Rose, Chassin, Presson, \& Sherman, 2000; Preacher \& Hayes, 2008). The present study used a bootstrapping approach to multiple mediation that does not impose such an assumption, a process that simultaneously increases power and maintains reasonable control over the Type I error rate (Preacher \& Hayes, 2008). Bootstrapping is a nonparametric resampling technique that empirically generates an approximation of the sampling distribution. In the case of multiple mediation models, sampling distributions of total and indirect effects are empirically generated by selecting a subsample, with replacement, of the full data set and then calculating indirect effects in the repeated subsamples. The procedure yields point estimates and percentile confidence intervals for indirect and total effects. In the present study, bootstrap percentile confidence intervals were further improved using bias-correction and acceleration, as recommended by Preacher and Hayes (2008). Lifetime history of SUD was entered as a covariate in each model. Controlling for lifetime history of SUD represents a conservative test of our hypothesis, because BAS sensitivity and/or IN score may represent vulnerabilities to lifetime SUDs as well as to prospective substance use problems.

Table 7 presents point estimates and bias-corrected and accelerated bootstrap confidence intervals based on 5,000 bootstrap samples, for both simple and multiple mediator models of our hypotheses. Tests of simple indirect effects (Table 7, top part) indicated that the relationship between bipolar spectrum diagnosis and prospectively assessed substance use problems was significantly mediated by BAS total, BAS Fun Seeking, and IN scores but not by BAS Drive, BAS Reward Responsiveness, or BIS scores. Conclusions drawn from an examination of the biascorrected and accelerated confidence intervals were consistent with results of a traditional product-of-coefficients approach: the Sobel test statistic was 1.81 for BAS total ( $p=.07), 2.86$ for BAS 
Table 5

Logistic Regression Models With BAS, BAS Subscales, IN, and the Interaction of BAS and BAS Subscales With IN Predicting Bipolar Spectrum Status

\begin{tabular}{|c|c|c|c|c|c|}
\hline Predictor & $\beta$ & $S E$ & Wald & OR & $95 \% \mathrm{CI}$ \\
\hline \multicolumn{6}{|l|}{ Model 1} \\
\hline \multicolumn{6}{|l|}{ Step 1} \\
\hline BAS total & .114 & .025 & 20.936 & $1.121^{* * * *}$ & $1.067-1.177$ \\
\hline \multicolumn{6}{|l|}{ Step 2} \\
\hline BAS total & .052 & .028 & 3.355 & 1.053 & $0.996-1.113$ \\
\hline IN & .119 & .020 & 36.188 & $1.126^{\text {**** }}$ & $1.083-1.170$ \\
\hline \multicolumn{6}{|l|}{ Step 3} \\
\hline BAS total & .050 & .028 & 3.199 & 1.052 & $0.995-1.111$ \\
\hline IN & .118 & .020 & 0.020 & $35.96^{* * * *}$ & $1.083-1.170$ \\
\hline BAS $\times$ IN & .002 & .004 & 0.287 & 1.002 & $0.995-1.009$ \\
\hline \multicolumn{6}{|l|}{ Model 2} \\
\hline \multicolumn{6}{|l|}{ Step 1} \\
\hline BAS Fun Seeking & .265 & .055 & 23.089 & $1.303^{* * * *}$ & $1.170-1.452$ \\
\hline \multicolumn{6}{|l|}{ Step 2} \\
\hline BAS Fun Seeking & .086 & .064 & 1.782 & 1.09 & $0.961-1.236$ \\
\hline IN & .120 & .020 & 34.206 & $1.127^{\text {**** }}$ & $1.083-1.173$ \\
\hline \multicolumn{6}{|l|}{ Step 3} \\
\hline BAS Fun Seeking & .087 & .064 & 1.836 & 1.09 & $0.962-1.236$ \\
\hline IN & .119 & .021 & 33.487 & $1.126^{* * *}$ & $1.082-1.172$ \\
\hline Fun Seeking $\times$ IN & .006 & .008 & 0.593 & 1.006 & $0.990-1.023$ \\
\hline \multicolumn{6}{|l|}{ Model 3} \\
\hline \multicolumn{6}{|l|}{ Step 1} \\
\hline BAS Drive & .205 & .053 & 14.893 & $1.228^{* * * *}$ & $1.106-1.363$ \\
\hline \multicolumn{6}{|l|}{ Step 2} \\
\hline BAS Drive & .087 & .061 & 2.064 & 1.091 & $0.969-1.230$ \\
\hline IN & .124 & .019 & 40.972 & $1.132^{* * * *}$ & $1.090-1.176$ \\
\hline \multicolumn{6}{|l|}{ Step 3} \\
\hline BAS Drive & .086 & .061 & 1.982 & 1.09 & $0.967-1.228$ \\
\hline IN & .124 & .019 & 40.671 & $1.132^{* * * *}$ & $1.089-1.175$ \\
\hline Drive $\times$ IN & .002 & .008 & 0.086 & 1.002 & $0.987-1.018$ \\
\hline \multicolumn{6}{|l|}{ Model 4} \\
\hline \multicolumn{6}{|l|}{ Step 1} \\
\hline BAS Reward & .148 & .063 & 5.615 & $1.16^{*}$ & $1.026-1.311$ \\
\hline \multicolumn{6}{|l|}{ Step 2} \\
\hline BAS Reward & .118 & .070 & 2.839 & 1.125 & $0.981-1.291$ \\
\hline IN & .129 & .019 & 47.584 & $1.138^{* * * *}$ & $1.097-1.181$ \\
\hline \multicolumn{6}{|l|}{ Step 3} \\
\hline BAS Reward & .118 & .070 & 2.841 & 1.125 & $0.981-1.289$ \\
\hline IN & .130 & .019 & 47.71 & $1.139^{\text {***** }}$ & $1.097-1.181$ \\
\hline Reward $\times$ IN & .006 & .009 & 0.371 & 1.006 & $0.987-1.024$ \\
\hline \multicolumn{6}{|l|}{ Model 5} \\
\hline \multicolumn{6}{|l|}{ Step 1} \\
\hline BIS & .058 & .035 & 2.745 & 1.06 & $1.026-1.311$ \\
\hline \multicolumn{6}{|l|}{ Step 2} \\
\hline BIS & .130 & .042 & 9.381 & $1.139^{* * *}$ & $0.981-1.291$ \\
\hline IN & .144 & .020 & 53.094 & $1.155^{\text {**** }}$ & $1.097-1.181$ \\
\hline \multicolumn{6}{|l|}{ Step 3} \\
\hline BIS & .130 & .043 & 9.371 & $1.139^{* *}$ & $0.981-1.289$ \\
\hline IN & .144 & .020 & 52.429 & $1.155^{\text {***** }}$ & $1.097-1.181$ \\
\hline $\mathrm{BIS} \times \mathrm{IN}$ & .000 & .005 & 0.021 & 0.999 & $0.987-1.024$ \\
\hline
\end{tabular}

Note. $\quad$ OR $=$ odds ratio; $95 \% \mathrm{CI}=95 \%$ confidence interval for odds ratio; BAS $=$ Behavioral Approach System Scale; BIS $=$ Behavioral Inhibition System Scale; IN = Impulsive Nonconformity Scale; Fun Seeking = Fun Seeking subscale; Drive = Drive subscale; Reward $=$ Reward Responsiveness subscale. In Model 1. Block $1, \chi^{2}(1, N=280)=23.657, p=.000$. In Model 1, Block 2, $\chi^{2}(1, N=280)=45.250$ for Step $1(p=.000)$ and $\chi^{2}(2, N=$ $280)=68.907$ for the model $(p=.000)$. In Model 1 , Block $3, \chi^{2}(1, N=280)=0.287$ for Step $1(p=.592)$ and $\chi^{2}(3, N=280)=69.195$ for the model $(p=.000)$. In Model 2, Block $1, \chi^{2}(1, N=285)=42.613(p=.000)$. In Model 2, Block $2, \chi^{2}(1, N=285)=42.613$ for Step $1(p=.000)$ and $\chi^{2}(2$, $N=285)=68.413$ for the model $(p=.000)$. In Model 2, Block 3, $\chi^{2}(1, N=285)=0.597$ for Step $1(p=.440)$ and $\chi^{2}(3, N=285)=69.010$ for the model $(p=.000)$. In Model 3, Block 1, $\chi^{2}(1, N=285)=16.083(p=.000)$. In Model 3, Block 2, $\chi^{2}(1, N=285)=52.199$ for Step $1(p=.000)$ and $\chi^{2}(2, N=285)=68.282$ for the model $(p=.000)$. In Model 3, Block 3, $\chi^{2}(1, N=285)=0.087$ for Step $1(p=.768)$ and $\chi^{2}(3, N=285)=68.369$ for the model $(p=.000)$. In Model 4, Block $1, \chi^{2}(1, N=283)=5.785(p=.016)$. In Model 4, Block 2, $\chi^{2}(1, N=283)=63.007$, for Step 1 $(p=.000)$ and $\chi^{2}(2, N=283)=68.792$ for the model $(p=.000)$. In Model 4, Block $3, \chi^{2}(1, N=283)=0.368$ for Step $1(p=.544)$ and $\chi^{2}(3$, $N=283)=69.160$ for the model $(p=.000)$. In Model 5, Block $1, \chi^{2}(1, N=285)=2.88, p=.095$. In Model $5, B$ lock $2, \chi^{2}(1, N=285)=$ 73.762 , for Step $1(p=.000)$ and $\chi^{2}(2, N=295)=68.792$ for the model $(p=.000)$. In Model 5, Block $3, \chi^{2}(1, N=285)=0.021$ for Step 1 $(p=.884)$ and $\chi^{2}(3, N=285)=76.572$ for the model $(p=.000)$.

* $p<.05$. *** $p<.01$. **** $p<.001$. 


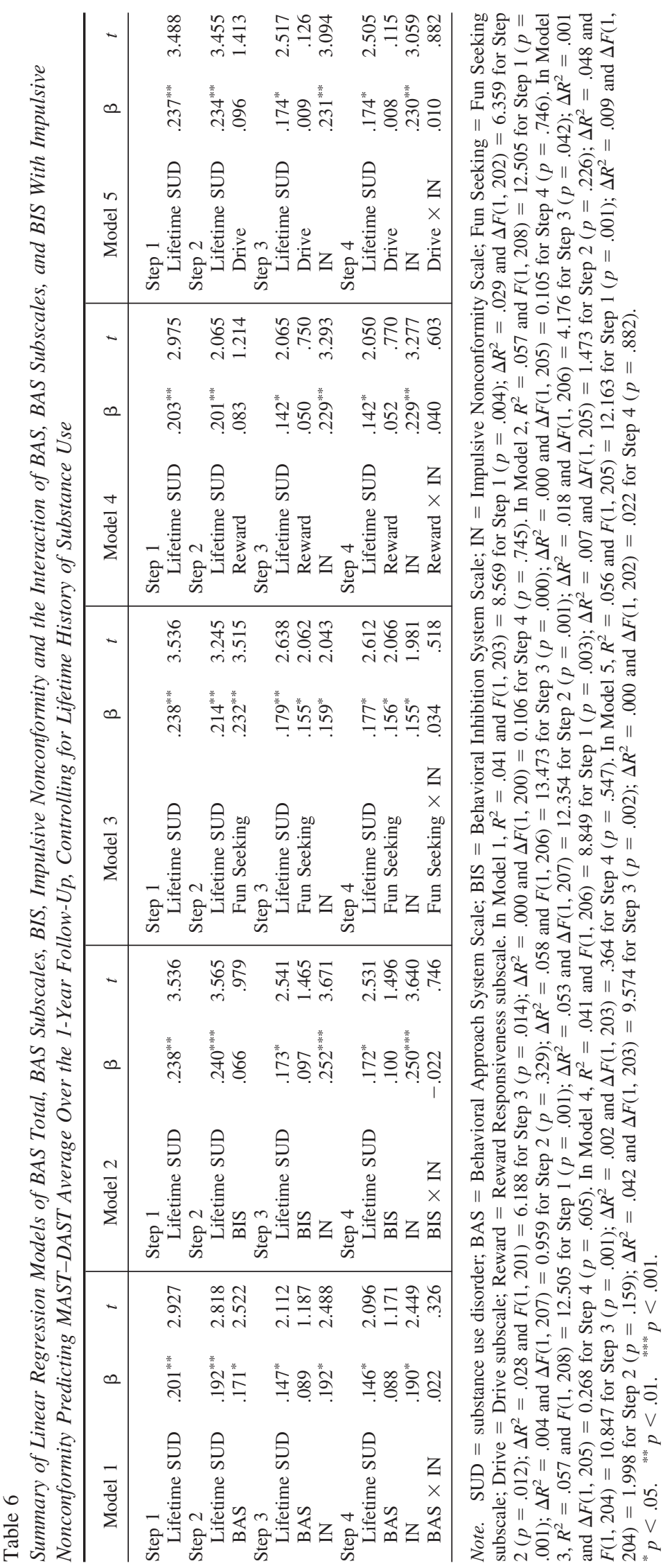


Table 7

Simple and Multiple Mediation of the Indirect Effects of Bipolar Spectrum Diagnosis on Prospective Substance Use Problems Through the Behavioral Approach System (BAS) Scale, BAS Subscales, Impulsive Nonconformity Scale, and Behavioral Inhibition System (BIS) Scale

\begin{tabular}{|c|c|c|c|}
\hline \multirow[b]{2}{*}{ Mediator or mediation model } & \multirow[b]{2}{*}{ Point estimate } & \multicolumn{2}{|c|}{$\mathrm{BCa} 95 \% \mathrm{CI}$} \\
\hline & & Lower & Upper \\
\hline \multicolumn{4}{|c|}{ Simple indirect effects } \\
\hline BAS total & $0.0899^{*}$ & 0.0029 & 0.2194 \\
\hline Fun Seeking & $0.1391^{*}$ & 0.0415 & 0.2815 \\
\hline Reward & 0.0296 & -0.0171 & 0.1168 \\
\hline Drive & 0.0264 & -0.0317 & 0.1189 \\
\hline Impulsiveness & $0.1747^{*}$ & 0.0418 & 0.1738 \\
\hline BIS & 0.0140 & -0.0226 & 0.0842 \\
\hline \multicolumn{4}{|c|}{ Multiple indirect effects } \\
\hline \multicolumn{4}{|l|}{ Model 1} \\
\hline \multicolumn{4}{|l|}{ Indirect effects } \\
\hline BAS total & 0.0493 & -0.0526 & 0.1636 \\
\hline Impulsiveness & $0.1401^{*}$ & 0.0008 & 0.3525 \\
\hline Total & $0.1895^{*}$ & 0.0353 & 0.3993 \\
\hline \multicolumn{4}{|l|}{ Contrasts } \\
\hline BAS total vs. Impulsiveness & -0.0908 & -0.3539 & 0.1013 \\
\hline \multicolumn{4}{|l|}{ Model 2} \\
\hline \multicolumn{4}{|l|}{ Indirect effects } \\
\hline Fun Seeking & 0.0966 & -0.0039 & 0.2287 \\
\hline Impulsiveness & 0.1118 & -0.0282 & 0.3454 \\
\hline Total & $0.2084^{*}$ & 0.0587 & 0.4289 \\
\hline \multicolumn{4}{|l|}{ Contrasts } \\
\hline Fun Seeking vs. Impulsiveness & -0.0152 & -0.2951 & 0.1905 \\
\hline \multicolumn{4}{|l|}{ Model 3} \\
\hline \multicolumn{4}{|l|}{ Indirect effects } \\
\hline Drive & 0.0010 & -0.0798 & 0.0744 \\
\hline Impulsiveness & $0.1748^{*}$ & 0.0342 & 0.3970 \\
\hline Total & $0.1757^{*}$ & 0.0309 & 0.3916 \\
\hline \multicolumn{4}{|l|}{ Contrasts } \\
\hline Drive vs. Impulsiveness & -0.1738 & -0.4178 & -0.0016 \\
\hline \multicolumn{4}{|l|}{ Model 4} \\
\hline \multicolumn{4}{|l|}{ Indirect effects } \\
\hline Reward Responsiveness & 0.0151 & -0.0341 & 0.0943 \\
\hline Impulsiveness & $0.1711^{*}$ & 0.0372 & 0.3905 \\
\hline Total & $0.1862^{*}$ & 0.0364 & 0.4186 \\
\hline \multicolumn{4}{|l|}{ Contrasts } \\
\hline Reward Responsiveness vs. Impulsiveness & -0.1560 & -0.3620 & -0.0121 \\
\hline \multicolumn{4}{|l|}{ Model 5} \\
\hline \multicolumn{4}{|l|}{ Indirect effects } \\
\hline BIS & 0.0248 & -0.0058 & 0.1103 \\
\hline Impulsiveness & $0.1964^{*}$ & 0.0523 & 0.4127 \\
\hline Total & $0.2212^{*}$ & 0.0622 & 0.4528 \\
\hline \multicolumn{4}{|l|}{ Contrasts } \\
\hline BIS vs. Impulsiveness & $0.1717^{*}$ & 0.0258 & 0.3829 \\
\hline
\end{tabular}

Note. $\quad \mathrm{BCa}=$ bias corrected and accelerated bootstrapping confidence intervals that include correction for median bias and skew. Confidence intervals containing zero are interpreted as being not significant. $* p<.05$.

Fun Seeking ( $p=.004)$, and 3.21 for IN $(p=.001)$. Sobel tests for all other simple mediation models were nonsignificant.

Bootstrapped tests of simultaneous multiple indirect effects were conducted to determine the unique ability of each putative mediator to account for the effects of bipolar diagnosis on prospective substance use problems. In other words, we examined whether the relationship between bipolar disorder and substance use problems was significantly mediated by (a) BAS total, BAS subscales, or BIS, even after controlling for IN scores, and (b) IN, even after controlling for the effects of BAS total, BAS subscales, or BIS. Results are presented in Table 7 . When entered simultaneously with IN score, BAS total and BAS Fun Seeking no longer significantly mediated the bipolar spectrum-prospective substance use relationship. Impulsiveness, however, remained as a significant mediator even when controlling for the simultaneous specific indirect effects through BAS, BAS Reward Responsiveness, BAS Drive, and BIS. The sum of the specific indirect effects (i.e., total indirect effects) was significant in all multiple mediation models. 
When contrasting specific indirect effects within each model, no significant differences were found between BAS total or BAS Fun Seeking and impulsiveness. Significant differences did emerge between specific indirect effects of (a) BAS Drive and impulsiveness and (b) BAS Reward Responsiveness and impulsiveness. A contrast of the specific indirect effects of BIS and impulsiveness was also significant. Of note, all confidence intervals constructed for interaction terms between the BIS/BAS Scales (BAS total, BAS subscales, or BIS) and IN contained zero, indicating nonsignificant interactions (consistent with the nonsignificant interaction effects shown in Tables 5 and 6). Moreover, inclusion of interaction terms in the multiple mediation models did not change the significance or direction of relationships between other variables.

\section{Discussion}

Our aim in the present study was to examine whether high BAS sensitivity and/or impulsiveness represent shared vulnerabilities to bipolar spectrum disorders and substance use problems. Consistent with prior evidence of high co-occurrence between bipolar disorders and SUDs (e.g., Conway et al., 2006; Grant et al., 2004), our initial analyses revealed that individuals with bipolar spectrum disorders were at elevated risk for lifetime SUDs and that they exhibited higher levels of prospective substance use problems. Specifically, in the large screening sample, individuals diagnosed with bipolar disorder (bipolar I, bipolar II, or cyclothymia) exhibited higher rates of lifetime SUDs than did those with either a history of unipolar major depression or no history of mood episodes. In addition, in the main analysis sample, bipolar spectrum status (bipolar II or cyclothymia) also prospectively predicted increased substance use problems over the 1-year follow-up, even after controlling for lifetime history of SUDs. Thus, the consistently reported association between bipolar disorder and SUD was conceptually replicated in our sample and extended with the more powerful prospective design. These results also allowed us to test the shared vulnerability hypothesis.

Consistent with Hypothesis 1, RST (Gray, 1982; Gray \& McNaughton, 2000), and the BAS dysregulation model (Depue \& Iacono, 1989; Depue et al., 1987; Urosevic et al., 2008), individuals with bipolar spectrum disorders, as compared with controls, exhibited significantly higher self-reported BAS sensitivity, as measured by BAS total, Drive, Fun Seeking, and Reward Responsiveness scores. This finding is consistent with the prior results of Alloy et al. (2008); in that study, high self-reported BAS sensitivity also predicted shorter time to onset of hypomanic/manic episodes among individuals with bipolar spectrum disorders. Our analyses revealed that BAS sensitivity (specifically, BAS total and Fun Seeking scores) continued to significantly predict bipolar spectrum diagnosis, even after controlling for initial symptom levels. High self-reported impulsiveness also predicted bipolar spectrum status, controlling for initial symptom levels. Thus, results are consistent with the hypothesis that both BAS sensitivity and impulsiveness may confer vulnerability to bipolar spectrum disorders.

Consistent with Hypothesis 2 and RST, both high self-reported BAS sensitivity and impulsiveness predicted greater substance use problems over the follow-up. As with bipolar spectrum status, it was again BAS total and Fun Seeking scores that specifically predicted prospectively assessed substance use problems, after controlling for lifetime SUD. It is important to note that controlling for lifetime history of SUDs represents a conservative test of our hypotheses, in that BAS sensitivity and/or impulsiveness may represent vulnerabilities to lifetime SUDs as well as to prospective substance use problems. Thus, results support our second hypothesis that BAS sensitivity and impulsiveness confer vulnerability to substance use problems. That the same BAS scale scores predicted both bipolar diagnosis and substance use further underscores a possible shared personality vulnerability between the two disorders.

In contrast with findings on BAS, findings on the role of BIS in bipolar disorder and SUD expression have been mixed (Alloy et al., 2008). In the present sample, BIS sensitivity did not predict either bipolar spectrum status or substance use problems over the follow-up. Our results add to research suggesting that BIS may not play a critical role in the expression of bipolar disorder and SUD. However, it is important to note that our measure of BIS (Carver \& White, 1994) was based on the 1982 version of RST and probably best assesses punishment sensitivity. It will be interesting to assess whether yet-to-be-developed measures of the revised RST's BIS may explain variance in bipolar disorder and SUDs.

With respect to our mediational hypotheses, BAS total, BAS Fun Seeking, and impulsiveness each predicted increased prospective substance use problems after controlling for lifetime history of SUD and bipolar spectrum status. Both bootstrapping methods and Sobel tests of mediation indicated that BAS total, BAS Fun Seeking, and impulsiveness all mediated the association between bipolar spectrum status and substance use problems. Thus, all three study hypotheses received support. Moreover, our bootstrapped tests of simultaneous multiple indirect effects indicated that BAS total and Fun Seeking no longer mediated the bipolar-substance use association controlling for impulsiveness, whereas impulsiveness continued to mediate bipolar-substance use co-occurrence controlling for BAS and BIS. BAS sensitivity (total or subscales) and impulsiveness did not interact to predict bipolar spectrum status, substance use problems, or their co-occurrence. Our mediational findings are consistent with the idea that although existing theory and research and the correlations between the BAS and IN instruments used in this study suggest that BAS sensitivity and impulsiveness are separate but overlapping constructs, it is the component of BAS sensitivity shared with impulsiveness that appears to be most important in mediating the co-occurrence of bipolar disorder with substance use.

It is of interest that in most analyses, BAS Fun Seeking scores were the strongest predictor among BAS total and subscale scores. Whereas BAS Drive assesses persistence in striving for goals and BAS Reward Responsiveness assesses responsiveness to obtained rewards (or consummatory, postgoal positive affect), the BAS Fun Seeking subscale assesses specifically the component of BAS sensitivity relating to willingness to approach new and potentially rewarding experiences (items include "I'm always willing to try something new if I think it will be fun" and "I crave excitement and new sensations"). Of the three BAS subscales, perhaps the BAS Fun Seeking subscale best captures anticipatory, pregoal positive affective processes that activate the nucleus accumbens (Knutson \& Wimmer, 2007), a structure rich in dopamine, a neurochemical implicated in BAS sensitivity (Depue \& Collins, 1999). It is important to note that the accumbens and dopamine 
have been found to be involved in drug addiction in animal research (Berridge, 2007).

To our knowledge, this is the first study to demonstrate that impulsiveness and BAS sensitivity mediate the association between bipolar spectrum disorders and prospectively assessed substance use problems. Findings are consistent with the hypothesis that high BAS sensitivity and impulsiveness represent shared vulnerabilities to both bipolar disorder and substance use problems, with the component of BAS sensitivity that overlaps with impulsiveness (i.e., BAS Fun Seeking) being most important in this shared vulnerability. Although the strength of association between the tested variables was modest, it is important to note that the shared vulnerability hypothesis likely explains only a portion of bipolar spectrum-substance use co-occurrence. As noted earlier, other potential explanations include the selfmedication hypothesis and the neuropsychological effects of repeated substance use over time.

Notable study strengths include the prospective assessment of substance use problems, the large sample size, interviewers blind to BIS/BAS Scales and impulsivity scores, and a unique contribution to the literatures on both RST and bipolar spectrum-substance use co-occurrence. Several study limitations should be noted as well. First, this study relied on self-report measures of BAS, impulsiveness, and substance use problems; future research should adopt a multimethod, multimeasure approach to the assessment of these constructs. In particular, it may be beneficial to assess additional dimensions of substance use, such as frequency and amount of use over the follow-up. A second limitation is that associations between bipolar spectrum diagnosis and BAS sensitivity and impulsiveness were examined cross-sectionally, although we previously demonstrated that BAS sensitivity predicted time to onset of prospectively assessed manic and hypomanic episodes (Alloy et al., 2008). Further studies are needed to determine whether BAS sensitivity and impulsiveness prospectively predict first lifetime onsets of bipolar disorder and SUD, to more precisely test the shared vulnerability hypothesis. Finally, in the present study, we examined prospective prediction of general substance use problems in an undergraduate sample. Participants experienced relatively low levels of mood symptomatology and substance use problems. Although it is noteworthy that shared vulnerability effects were demonstrated even in this relatively high-functioning sample, further research is needed to replicate findings in other samples.

In conclusion, the present study adds to a growing body of research implicating both BAS sensitivity and impulsiveness in bipolar and SUDs. Results support the central importance of heightened impulsiveness and components of BAS sensitivity that overlap with impulsiveness in both bipolar disorders and SUDs. Moreover, findings are consistent with the shared personality vulnerability hypothesis and indicate that the hypothesis warrants further evaluation. Understanding the role of these personality vulnerabilities may be especially important, as they represent potential points of behavioral intervention.

\section{References}

Acton, G. (2003). Measurement of impulsivity in a hierarchical model of personality traits: Implications for substance use. Substance Use \& Misuse, 38, 67-83.
Allen, J., Iacono, W., Depue, R., \& Arbisi, P. (1993). Regional electroencephalographic asymmetries in bipolar seasonal affective disorder before and after exposure to bright light. Biological Psychiatry, 33, 642646.

Alloy, L. B., Abramson, L. Y., Hogan, M. E., Whitehouse, W. G., Rose, D. T., Robinson, M. S., et al. (2000). The Temple-Wisconsin Cognitive Vulnerability to Depression Project: Lifetime history of Axis I psychopathology in individuals at high and low cognitive risk for depression. Journal of Abnormal Psychology, 109, 403-418.

Alloy, L. B., Abramson, L. Y., Walshaw, P. D., Cogswell, A., Grandin, L. D., Hughes, M., et al. (2008). Behavioral approach system and behavioral inhibition system sensitivities and bipolar spectrum disorders: Prospective prediction of bipolar mood episodes. Bipolar Disorders, 10, 310-322.

Alloy, L. B., Abramson, L. Y., Walshaw, P. D., Cogswell, A., Smith, J. B., Neeren, A. M., et al. (2006). Behavioral approach system (BAS) sensitivity and bipolar spectrum disorders: A retrospective and concurrent behavioral high-risk design. Motivation and Emotion, 30, 143-155.

Alloy, L. B., Abramson, L. Y., Walshaw, P. D., Gerstein, R. K., Keyser, J. D., Whitehouse, W. G., et al. (in press). Behavioral approach system (BAS)-relevant cognitive styles and bipolar spectrum disorders: Concurrent and prospective associations. Journal of Abnormal Psychology.

Alloy, L. B., Reilly-Harrington, N. A., Fresco, D., Whitehouse, W. G., \& Zechmeister, J. A. (1999). Cognitive styles and life events in subsyndromal unipolar and bipolar mood disorders: Stability and prospective prediction of depressive and hypomanic mood swings. Journal of Cognitive Psychotherapy: An International Quarterly, 13, 21-40.

American Psychiatric Association. (1994). Diagnostic and statistical manual of mental disorders (4th ed.). Washington, DC: American Psychiatric Association.

Baron, R. M., \& Kenny, D. A. (1986). The moderator-mediator variable distinction in social psychological research: Conceptual, strategic, and statistical considerations. Journal of Personality and Social Psychology, 51, 1173-1182.

Bechara, A., \& Damasio, H. (2002). Decision-making and addiction (Part I): Impaired activation of somatic states in substance dependent individuals when pondering decisions with negative future consequences. $\mathrm{Neu}$ ropsychologia, 40, 1675-1689.

Bechara, A., Dolan, S., \& Hindes, A. (2002). Decision-making and addiction (Part II): Myopia for the future or hypersensitivity to reward? Neuropsychologia, 40, 1690-1705.

Beck, A. T., Rush, A. J., Shaw, B. F., \& Emery, G. (1979). Cognitive therapy of depression. New York: Guilford Press.

Beck, A. T., Steer, R. A., \& Garbin, M. G. (1988). Psychometric properties of the Beck Depression Inventory: Twenty-five years of evaluation. Clinical Psychology Review, 8, 77-100.

Berridge, K. C. (2007). The debate over dopamine's role in reward: The case for incentive salience. Psychopharmacology, 191, 391-431.

Blum, K., Braverman, E. R., Holder, J. M., Lubar, J. F., Monastra, V. J., Miller, D., et al. (2000). Reward deficiency syndrome: A biogenetic model for the diagnosis and treatment of impulsive, addictive, and compulsive behaviors. Journal of Psychoactive Drugs, 32(Suppl. i-iv), $1-112$.

Campbell-Sills, L., Liverant, G. I., \& Brown, T. A. (2004). Psychometric evaluation of the Behavioral Inhibition/Behavioral Activation Scales in a large sample of outpatients with anxiety and mood disorders. Psychological Assessment, 16, 244-254.

Carver, C. S. (2004). Negative affect deriving from the behavioral approach system. Emotion, 4, 3-22.

Carver, C. S., \& White, T. L. (1994). Behavioral inhibition, behavioral activation, and affective responses to impending reward and punishment: The BIS/BAS Scales. Journal of Personality and Social Psychology, 67, 319-333.

Chambers, R. A., Taylor, J. R., \& Potenza, M. N. (2003). Developmental 
neurocircuitry of motivation in adolescence: A critical period of addiction vulnerability. American Journal of Psychiatry, 160, 1041-1052.

Chapman, L. J., Chapman, J. P., Numbers, J. S., Edell, W. S., Carpenter, B. N., \& Beckfield, D. (1984). Impulsive nonconformity as a trait contributing to the prediction of psychotic-like and schizotypal symptoms. Journal of Nervous and Mental Disease, 172, 681-691.

Chiara, G. D. (1995). The role of dopamine in drug abuse viewed from the perspective of its role in motivation. Drug and Alcohol Dependence, 38, 95-137.

Cloninger, C. R., Przybeck, T. R., Svrakic, D. M., \& Wetzel, R. D. (1994). The temperament and character inventory (TCI): A guide to its development and use. St. Louis, MO: Center for Psychobiology of Personality.

Coan, J. A., \& Allen, J. J. B. (2004). Frontal EEG asymmetry as a moderator and mediator of emotion. Biological Psychology, 67, 7-49.

Cocco, K. M., \& Carey, K. B. (1998). Psychometric properties of the drug abuse screening test in psychiatric outpatients. Psychological Assessment, 10, 408-414.

Colder, C. R., \& O'Connor, R. (2002). Attention biases and disinhibited behavior as predictors of alcohol use and enhancement reasons for drinking. Psychology of Addictive Behaviors, 16, 325-332.

Colder, C. R., \& O'Connor, R. M. (2004). Gray's reinforcement sensitivity model and child psychopathology: Laboratory and questionnaire assessment of the BAS and BIS. Journal of Abnormal Child Psychology, 32, 435-451.

Conley, T. B. (2001). Construct validity of the MAST and AUDIT with multiple offender drunk drivers. Journal of Substance Abuse Treatment, 20, 287-295.

Conway, K. P., Compton, W., Stinson, F. S., \& Grant, B. F. (2006). Lifetime comorbidity of $D S M-I V$ mood and anxiety disorders and specific drug use disorders: Results from the National Epidemiologic Survey on Alcohol and Related Conditions. Journal of Clinical Psychiatry, $67,247-257$.

Corr, P. J. (2008). Reinforcement sensitivity theory (RST): Introduction. In P. J. Corr (Ed.), The reinforcement sensitivity theory of personality (pp. 1-43). New York: Cambridge University Press.

Dalton, E. J., Cate-Carter, T. D., Mundo, E., Parikh, S. V., \& Kennedy, J. L. (2003). Suicide risk in bipolar patients: The role of co-morbid substance use disorders. Bipolar Disorders, 5, 58-61.

Davidson, R. J., Jackson, D. C., \& Kalin, N. H. (2000). Emotion, plasticity, context, and regulation: Perspectives from affective neuroscience. Psychological Bulletin, 126, 890-909.

Dawe, S., Gullo, M. J., \& Loxton, N. J. (2004). Reward drive and rash impulsiveness as dimensions of impulsivity: Implications for substance misuse. Addictive Behaviors, 29, 1389-1405.

Dawe, S., \& Loxton, N. J. (2004). The role of impulsivity in the development of substance use and eating disorders. Neuroscience and Biobehavioral Reviews, 28, 343-351.

Depue, R. A. (1985). Behavioral Variability Interview. Minneapolis: University of Minnesota Twin Cities Campus.

Depue, R. A., \& Collins, P. F. (1999). Neurobiology of the structure of personality: Dopamine, facilitation of incentive motivation, and extraversion. Behavioral and Brain Sciences, 22, 491-517.

Depue, R. A., \& Iacono, W. G. (1989). Neurobehavioral aspects of affective disorders. Annual Review of Psychology, 40, 457-492.

Depue, R. A., Krauss, S., \& Spoont, M. R. (1987). A two-dimensional threshold model of seasonal bipolar affective disorder. In D. Magnusson \& A. Ohman (Eds.), Psychopathology: An interactional perspective (pp. 95-123). New York: Academic Press.

Depue, R. A., Krauss, S., Spoont, M. R., \& Arbisi, P. (1989). General Behavior Inventory identification of unipolar and bipolar affective conditions in a nonclinical population. Journal of Abnormal Psychology, 98, $117-126$.

Depue, R. A., Slater, J. F., Wolfstetter-Kausch, H., Klein, D., Goplerud, E.,
\& Farr, D. (1981). A behavioral paradigm for identifying persons at risk for bipolar depressive disorder: A conceptual framework and five validation studies. Journal of Abnormal Psychology, 90, 381-437.

El-Bassel, N., Schilling, R. F., Schinke, S., Orlandi, M., Sun, W. H., \& Back, S. (1997). Assessing the utility of the drug abuse screening test in the workplace. Research for Social Work Practice, 7, 99-114.

Endicott, J., \& Spitzer, R. L. (1978). A diagnostic interview: The Schedule of Affective Disorders and Schizophrenia. Archives of General Psychiatry, 35, 837-844.

Eysenck, H. J., \& Eysenck, S. B. G. (1991). Manual of the Eysenck Personality Scales. London: Hodder \& Stoughton.

Fowles, D. C. (1987). Application of a behavioral theory of motivation to the concepts of anxiety and impulsivity. Journal of Research in Personality, 21, 417-435.

Fowles, D. C. (1993). Behavioral variables in psychopathology: A psychobiological perspective. In P. B. Sutker \& H. E. Adams (Eds.), Comprehensive handbook of psychopathology (pp. 57-82). New York: Plenum Press.

Francis-Raniere, E., Alloy, L. B., \& Abramson, L. Y. (2006). Depressive personality styles and bipolar spectrum disorders: Prospective tests of the event congruency hypothesis. Bipolar Disorders, 8, 382-399.

Franken, I. H. A. (2002). Behavioral approach system (BAS) sensitivity predicts alcohol craving. Personality and Individual Differences, 32, 349-355.

Franken, I. H. A., \& Muris, P. (2006). BIS/BAS personality characteristics and college students' substance use. Personality and Individual Differences, 40, 1497-1503.

Franken, I. H. A., Muris, P., \& Georgieva, I. (2006). Gray's model of personality and addiction. Addictive Behaviors, 31, 399-403.

Goldstein, R. Z., \& Volkow, N. D. (2002). Drug addiction and its underlying neurobiological basis: Neuroimaging evidence for the involvement of the frontal cortex. American Journal of Psychiatry, 159, 1642-1652.

Gotlib, I. H., Ranganath, C., \& Rosenfeld, J. P. (1998). Frontal EEG alpha asymmetry, depression, and cognitive functioning. Cognition and Emotion, 12, 449-478.

Grant, B. F., Stinston, F. S., Dawson, D. A., Chou, P., Dufour, M. C., Compton, W., et al. (2004). Prevalence and co-occurrence of substance use disorders and independent mood and anxiety disorders: Results from the National Epidemiologic Survey on Alcohol and Related Conditions. Archives of General Psychiatry, 61, 807-816.

Gray, J. A. (1982). The neuropsychology of anxiety: An enquiry into the functions of the septo-hippocampal system. New York: Oxford University Press.

Gray, J. A. (1991). Neural systems, emotion and personality. In J. Madden (Ed.), Neurobiology of learning, emotion and affect (pp. 273-306). New York: Raven Press.

Gray, J. A. (1994). Three fundamental emotion systems. In P. Eckman \& R. J. Davidson (Eds.), The nature of emotion: Fundamental questions (pp. 243-247). New York: Oxford University Press.

Gray, J. A., \& McNaughton, (2000). The neuropsychology of anxiety: An enquiry into the functions of the septo-hippocampal system. Oxford, England: Oxford University Press.

Harmon-Jones, E., Abramson, L. Y., Nusslock, R., Sigelman, J. D., Urosevic, S., Turonie, L. D., et al. (2008). Effect of bipolar disorder on left frontal cortical responses to goals differing in valence and task difficulty. Biological Psychiatry, 63, 693-698.

Harmon-Jones, E., Abramson, L. Y., Sigelman, J., Bohlig, J., Hogan, M. E., \& Harmon-Jones, C. (2002). Proneness to hypomania/mania symptoms or depression symptoms and asymmetrical frontal cortical responses to an anger-evoking event. Journal of Personality and Social Psychology, 82, 610-618.

Harmon-Jones, E., \& Allen, J. J. B. (1997). Behavioral activation sensitivity and resting frontal EEG asymmetry: Covariation of putative indi- 
cators related to risk for mood disorders. Journal of Abnormal Psychology, 106, 159-163.

Harmon-Jones, E., \& Allen, J. J. B. (1998). Anger and prefrontal brain activity: EEG asymmetry consistent with approach motivation despite negative affective valence. Journal of Personality and Social Psychology, 74, 1310-1316.

Harmon-Jones, E., \& Sigelman, J. (2001). State anger and prefrontal brain activity: Evidence that insult-related relative left prefrontal activity is associated with experienced anger and aggression. Journal of Personality and Social Psychology, 80, 797-803.

Harmon-Jones, E., Sigelman, J. D., Bohlig, A., \& Harmon-Jones, C. (2003). Anger, coping, and frontal cortical activity: The effect of coping potential on anger-induced left frontal activity. Cognition and Emotion, 17, 1-24.

Hayden, E. P., Wiegand, R. E., Meyer, E. T., Bauer, L. O., O'Connor, S. J., Nurnberger, J., et al. (2006). Patterns of regional brain activity in alcohol-dependent subjects. Alcoholism: Clinical and Experimental Research, 30, 1986-1991.

Henriques, J. B., \& Davidson, R. J. (1990). Regional brain electrical asymmetries discriminate between previously depressed and healthy control subjects. Journal of Abnormal Psychology, 99, 22-31.

Henriques, J. B., \& Davidson, R. J. (1991). Left frontal hypoactivation in depression. Journal of Abnormal Psychology, 100, 535-545.

Jentsch, J. D., \& Taylor, J. R. (1999). Impulsivity resulting from frontostriatal dysfunction in drug abuse: Implications for the control of behavior by reward-related stimuli. Psychopharmacology, 146, 373-390.

Johnson, S. L., Cuellar, A. K., Ruggero, C., Winett-Perlman, C., Goodnick, P., White, R., \& Miller, I. (2008). Life events as predictors of mania and depression in bipolar I disorder. Journal of Abnormal Psychology, 117, $268-277$.

Johnson, S. L., Sandrow, S. D., Meyer, B., Winters, R., Miller, I., Solomon, D., et al. (2000). Increases in manic symptoms after life events involving goal attainment. Journal of Abnormal Psychology, 109, 721-727.

Johnson, S. L., Turner, R. J., \& Iwata, N. (2003). BIS/BAS levels and psychiatric disorder: An epidemiological study. Journal of Psychopathology and Behavioral Assessment, 25, 25-36.

Kambouropoulos, N., \& Staiger, P. K. (2001). The influence of sensitivity to reward on reactivity to alcohol-related cues. Addiction, 96, 11751185.

Kambouropoulos, N., \& Staiger, P. K. (2004). Reactivity to alcohol-related cues: Relationship among cue type, motivational processes, and personality. Psychology of Addictive Behaviors, 18, 275-283.

Kano, K., Nakamura, M., Matsuoka, T., Lida, H., \& Nakajima, T. (1992). The topographical features of EEGs in patients with affective disorders. Electroencephalography and Clinical Neurophysiology, 83, 124-129.

Kasch, K. L., Rottenberg, J., Arnow, B. A., \& Gotlib, I. H. (2002). Behavioral activation and inhibition systems and the severity and course of depression. Journal of Abnormal Psychology, 111, 589-597.

Klamen, D. L., \& Miller, N. S. (1997). Undergraduate medical education in psychiatry and primary care. Psychiatric Annals, 27, 436-439.

Klein, D. N., Depue, R. A., \& Slater, J. F. (1986). Inventory identification of cyclothymia: IX. Validation in offspring of bipolar I patients. Archives of General Psychiatry, 43, 441-445.

Knutson, B., \& Wimmer, G. E. (2007). Reward: Neural circuitry for social valuation. In E. Harmon-Jones, \& P. Winkielman (Eds.), Social neuroscience: Integrating biological and psychological explanations of social behavior (pp. 157-175). New York: Guilford Press.

Knyazev, G. G. (2004). Behavioural activation as predictor of substance use: Mediating and moderating role of attitudes and social relationships. Drug and Alcohol Dependence, 75, 309-321.

Kwapil, T. R., Miller, M. B., Zinser, M. C., Chapman, L. J., \& Eckblad, M. (2000). A longitudinal study of high scorers on the Hypomanic Personality Scale. Journal of Abnormal Psychology, 109, 222-226.
Lam, D., Wright, K., \& Smith, N. (2004). Dysfunctional assumptions in bipolar disorder. Journal of Affective Disorders, 79, 193-199.

Lin, S. K., Lee, C. H., Pan, C. H., \& Hu, W. H. (2003). Comparison of the prevalence of substance use and psychiatric disorders between government and self-employed commercial drivers. Psychiatry and Clinical Neurosciences, 57, 425-431.

Loxton, N. J., \& Dawe, S. (2001). Alcohol abuse and dysfunctional eating in adolescent girls: The influence of individual differences in sensitivity to reward and punishment. Eating Disorders, 29, 455-462.

Loxton, N. J., \& Dawe, S. (2006). Reward and punishment sensitivity in dysfunctional eating and hazardous drinking women: Associations with family risk. Appetite, 47, 361-371.

Lozano, B. E., \& Johnson, S. L. (2001). Can personality traits predict increases in manic and depressive symptoms? Journal of Affective Disorders, 63, 103-111.

MacKinnon, D. P., Rose, J. S., Chassin, L., Presson, C. C., \& Sherman, S. J. (2000). Contrasts in multiple mediator models. In J. S. Rose, L. Chassin, C. C. Presson, \& S. J. Sherman (Eds.), Multivariate applications in substance use research: New methods for new questions (pp. 141-160). Mahwah, NJ: Erlbaum.

Maisto, S. A., Connors, G. J., \& Allen, J. P. (1995). Contrasting self-report screens for alcohol problems: A review. Alcoholism: Clinical and Experimental Research, 19, 1510-1516.

Mallon, J. C., Klein, D. N., Bornstein, R. F., \& Slater, J. F. (1986). Discriminant validity of the General Behavior Inventory: An outpatient study. Journal of Personality Assessment, 50, 568-577.

Marion, L. N., Fuller, S. G., Johnson, N. P., Michels, P. J., \& Diniz, C. (1996). Drinking problems in nursing students. Journal of Nursing Education, 35, 196-203.

McCann, B. S., Simpson, T. L., Ries, R., \& Roy-Byrne, P. (2000). Reliability and validity of screening instruments for drug and alcohol abuse in adults seeking evaluation for attention-deficit/hyperactivity disorder. American Journal on Addictions, 9, 1-9.

McFarland, B. R., Shankman, S. A., Tenke, C. E., Bruder, G. E., \& Klein, D. N. (2006). Behavioral activation system deficits predict the six-month course of depression. Journal of Affective Disorders, 91, 229-234.

Meyer, B., Johnson, S. L., \& Carver, C. S. (1999). Exploring behavioral activation and inhibition among college students at risk for bipolar spectrum symptomatology. Journal of Psychopathology and Behavioral Assessment, 21, 275-292.

Meyer, B., Johnson, S. L., \& Winters, R. (2001). Responsiveness to threat and incentive in bipolar disorder: Relations of the BIS/BAS scales with symptoms. Journal of Psychopathology and Behavioral Assessment, 23, 133-143.

Meyer, T. D., \& Hofmann, B. U. (2005). Assessing the dysregulation of the behavioral activation system: The Hypomanic Personality Scale and the BIS-BAS Scales. Journal of Personality Assessment, 85, 318-324.

Nusslock, R., Abramson, L. Y., Harmon-Jones, E., Alloy, L. B., \& Hogan, M. E. (2007). A goal-striving life event and the onset of bipolar episodes: Perspective from the behavioral approach system (BAS) dysregulation theory. Journal of Abnormal Psychology, 116, 105-115.

Nusslock, R., Alloy, L. B., Abramson, L. Y., Harmon-Jones, E., \& Hogan, M. E. (2008). Impairment in the achievement domain in bipolar spectrum disorders: Role of behavioral approach system hypersensitivity and impulsivity. Minerva Pediatrica, 60, 41-50.

Palfai, T. P., \& Ostafin, B. D. (2003). Alcohol-related motivational tendencies in hazardous drinkers: Assessing implicit response tendencies using the modified-IAT. Behaviour Research and Therapy, 41, 11491162.

Patton, J. H., Stanford, M. S., \& Barratt, E. S. (1995). Factor structure of the Barratt Impulsiveness Scale. Journal of Clinical Psychology, 51, $768-774$.

Pickering, A. D., \& Smillie, L. D. (2008). The behavioural activation system: Challenges and opportunities. In P. J. Corr (Ed.), The reinforce- 
ment sensitivity theory of personality (pp. 120-154). New York: Cambridge University Press.

Pinto-Meza, A., Caseras, S., Soler, J., Puigdemont, D., Perez, V., \& Torrubia, R. (2006). Behavioural inhibition and behavioural activation systems in current and recovered major depression participants. Personality and Individual Differences, 40, 215-226.

Preacher, K. J., \& Hayes, A. F. (2008). Asymptotic and resampling strategies for assessing and comparing indirect effects in multiple mediator models. Behavior Research Methods, 40, 879-891.

Raimo, E. B., \& Schuckit, M. A. (1998). Alcohol dependence and mood disorders. Addictive Behaviors, 23, 933-946.

Regier, D. A., Farmer, M. E., Rae, D. S., Locke, B. Z., Keith, S. J., Judd, L. L., et al. (1990). Comorbidity of mental disorders with alcohol and other drug abuse: Results from the Epidemiologic Catchment Area (ECA) Study. JAMA, 264, 2511-2518.

Salloum, I. M., \& Thase, M. E. (2000). Impact of substance abuse on the course and treatment of bipolar disorder. Bipolar Disorders, 2, 269-280.

Scott, J., Stanton, B., Garland, A., \& Ferrier, I. N. (2000). Cognitive vulnerability in patients with bipolar disorder. Psychological Medicine, 30, 467-472.

Selzer, M. L. (1971). The Michigan Alcoholism Screening Test: The quest for a new diagnostic instrument. American Journal of Psychiatry, 127, $1653-1658$

Shapiro, R. W., \& Keller, M. B. (1979). Longitudinal Interval Follow-up Evaluation (LIFE). Boston: Massachusetts General Hospital.

Shields, A. L., Howell, R. T., Potter, J. S., \& Weiss, R. D. (2007). The Michigan Alcoholism Screening Test and its shortened form: A metaanalytic inquiry into score reliability. Substance Use \& Misuse, 42, $1783-1800$

Skinner, H. A. (1992). The Drug Abuse Screening Test. Addictive Behaviors, 7, 363-371.

Sobel, M. E. (1982). Asymptotic confidence intervals for indirect effects in structural equation models. In S. Leinhardt (Ed.), Sociological methodology (pp. 290-312). San Francisco: Jossey-Bass.

Sobel, M. E. (1986). Some new results on indirect effects and their standard errors in covariance structure models. In N. Tuma (Ed.), Sociological methodology (pp. 159-186). Washington DC: American Sociological Association.

Sobotka, S. S., Davidson, R. J., \& Senulis, J. A. (1992). Anterior brain electrical asymmetries in response to reward and punishment. Electroencephalography and Clinical Neurophysiology, 83, 236-247.

Spitzer, R. L., \& Endicott, J. (1978). Schedule for Affective Disorders and Schizophrenia, Change version. New York: New York State Psychiatric Institute, Biometrics Research Division, Evaluation Section.

Spitzer, R. L., Endicott, J., \& Robins, E. (1978). Research Diagnostic
Criteria (RDC) for a selected group of functional disorders (3rd ed.). New York: New York Psychiatric Institute.

Strakowski, S. M., DelBello, M. P., Fleck, D. E., Adler, C., Anthenelli, R., Keck, P., et al. (2007). Effects of co-occurring cannabis use disorders on the course of bipolar disorder after a first hospitalization for mania. Archives of General Psychiatry, 64, 57-64.

Sutton, S. K., \& Davidson, R. J. (1997). Prefrontal brain asymmetry: A biological substrate of the behavioral approach and inhibition systems. Psychological Science, 8, 204-210.

Swann, A. C., Anderson, J. C., Dougherty, D. M., \& Moeller, F. G. (2001). Measurement of inter-episode impulsivity in bipolar disorder. Psychiatry Research, 101, 95-197.

Swann, A. C., Dougherty, D. M., Pazzaglia, P., Pham, M., \& Moeller, F. G. (2004). Impulsivity: A link between bipolar disorder and substance abuse. Bipolar Disorders, 6, 204-212.

Swann, A. C., Pazzaglia, P., Nicholls, A., Dougherty, D. M., \& Moeller, F. G. (2003). Impulsivity and phase of illness in bipolar disorder. Journal of Affective Disorders, 73, 105-111.

Torrubia, R., Avila, C., Molto, J., \& Caseras, X. (2001). The Sensitivity to Punishment and Sensitivity to Reward Questionnaire (SPSRQ) as a measure of Gray's anxiety and impulsivity dimensions. Personality and Individual Differences, 31, 837-862.

Urosevic, S., Abramson, L. Y., Harmon-Jones, E., \& Alloy, L. B. (2008), Dysregulation of the behavioral approach system (BAS) in bipolar spectrum disorders: Review of theory and evidence. Clinical Psychology Review, 28, 1188-1205.

Watson, C. G., Detra, E., Fox, K. L., \& Ewing, J. W. (1995). Comparative concurrent validates of five alcoholism measures in a psychiatric hospital. Journal of Clinical Psychology, 51, 676-684.

Wilens, T. E., Biederman, J., Kwon, A., Ditterline, J., Forkner, P., Moore, H., et al. (2004). Risk of substance use disorders in adolescents with bipolar disorder. Journal of the American Academy of Child and Adolescent Psychiatry, 43, 1380-1386.

Zinbarg, R. E., \& Mohlman, J. (1998). Individual differences in the acquisition of affectively valenced associations. Journal of Personality and Social Psychology, 74, 1024-1040.

Zinser, M. C., Fiore, M. C., Davidson, R. J., \& Baker, T. B. (1999). Manipulating smoking motivation: Impact on an electrophysiological index of approach motivation. Journal of Abnormal Psychology, 108, 240-254.

Zuckerman, M. (1994). Behavioural expressions and biosocial bases of sensation seeking. New York: Cambridge University Press.

Received October 21, 2008

Revision received March 12, 2009

Accepted March 17, 2009 